\title{
Indentation of polyethylene laminates by a flat-bottomed cylindrical punch
}

\author{
M.R. O’Masta ${ }^{\mathrm{a},{ }^{*}}$, D.H. Crayton ${ }^{\mathrm{a}}$, V.S. Deshpande ${ }^{\mathrm{b}}$ and H.N.G. Wadley ${ }^{\mathrm{a}}$ \\ ${ }^{a}$ Department of Material Science \& Engineering, School of Engineering and Applied Science, University of \\ Virginia, Charlottesville, VA 22904, USA \\ ${ }^{\mathrm{b}}$ Cambridge University Engineering Department, Trumpington Street, Cambridge CB2 1PZ, UK
}

\begin{abstract}
Cross-ply polymer laminates reinforced by ultra-high molecular weight polyethylene (UHWMPE) fibers and tapes have been subjected to quasi-static indentation by a flat-bottomed, circular cross section punch and their penetration resistance and failure mechanisms investigated. Three fiber- and two tapereinforced grades progressively failed during indentation via a series of unstable failure events accompanied by substantial load drops. This resulted in a 'saw-tooth' load versus indentation depth profile as the load increased with indentation depth after each failure event. The penetration behavior scaled with the ratio of the thickness of the remaining laminate to the diameter of the punch, and the indentation pressure scaled with the through thickness compressive strength. Failure occurred by ply rupture. The results are consistent with penetration governed by an indirect tension failure mechanism, and with experimental reports that tapereinforced materials have a similar ballistic resistance to the higher tensile strength fiber-reinforced grades in rear-supported test conditions.
\end{abstract}

Keywords: A. Laminates; A. Polymer-matrix composites (PMCs); D. Failure; D. Mechanical testing

* Corresponding author; M.R. O’Masta; E-mail address: mro4h@virginia.edu

(C) 2015. This manuscript version is made available under the Elsevier user license http://www.elsevier.com/open-access/userlicense/1.0/ 


\section{Introduction}

High performance fiber reinforced polymer matrix composites exhibit high impact resistance. The most promising consist of a $\left[0^{\circ} / 90^{\circ}\right]$ lamination of unidirectional plies each comprised of a high specific stiffness and tensile strength reinforcement dispersed within a low volume fraction, compliant polymer matrix [1]. Fibers of interest include those based upon carbon, S2 glass, Kevlar and ultra-high molecular weight (UHMWPE) which have high values of the Cuniff index [2,3]. Recent studies of the impact of thick, edge clamped UHMWPE laminates revealed the existence of two stages of projectile penetration [4,5]. Penetration was initially progressive, with the depth of penetration increasing linearly with impact velocity $[4,6-8]$. Little evidence of macroscopic out of plane plate deflection was found during this stage, and the mechanism of penetration was similar to that for a rear supported plate (with suppressed out of plane deflection) $[3,8,9]$. As progressive penetration was eventually arrested, a second mechanism of response became activated. This involved membrane stretching with significant out-of-plane deflection and a binary survival probability. This stage absorbed many times more impact energy per unit penetration distance than the initial, progressive penetration stage $[4,5]$.

While progressive penetration of glass- and carbon-fiber reinforced composites, at both quasi-static (Q.S.) and dynamic loading rates, is controlled by shear plug crack propagation ahead of the indenter tip [1016], direct observational evidence of shear plugging in UHWMPE composites at either quasi-static or dynamic rates has not be found in the literature $[3,6,8,9,11]$. To provide insight into the progressive penetration mechanism, Atwood et al. [17] have investigated UHWMPE cross-ply laminates placed under transverse (through the thickness) uniform compression, and shown that they fail by tensile rupture of the fibers. The plies respond to compression by plastic Poisson expansion in the direction transverse to their reinforcement direction, while Poisson expansion in the fiber direction is small due to the very high stiffness of the fibers. This highly anisotropic Poisson expansion causes each $0^{\circ}$ ply to load the $90^{\circ}$ plies above and below in tension in the reinforcement direction, and vice versa, Fig. 1. The stress is transferred between plies via a shear lag mechanism, and a ply fails when the tensile strength of the ply is reached. This indirect tension model predicts the significant sample size dependence of the laminates (through thickness) compression 
strength, and the observed increases in uniform compressive strength of UMWPE fiber reinforced laminates with increases in inter-laminar shear strength, increases in fiber strength and decreases in ply thicknesses $[17,18]$. The model has also helped rationalize the significant variability in laminate compressive strength arising from variability in ply thickness and missing fibers within the laminates [18].

Recent experimental studies with UHMWPE laminates reinforced with solid-state tapes rather than fibers have shown that they possess a substantially higher compressive strength than that predicted by the fiber indirect tension model [8]. It has been argued that the out of plane compressive strength of these tapes is governed by elastic inter-laminar shear behavior, rather than the plastic shear behavior observed in the fiber based systems [18]. This progressive mode of penetration is investigated here for a variety of fiber and tape $\left[0^{\circ} / 90^{\circ}\right]$ laminates since its suppression is expected to significantly improve the impact resistance of a plate. A flat bottomed, cylindrical punch is used to quasi-statically penetrate rear supported, $\left[0^{\circ} / 90^{\circ}\right]$ composite laminates. The effects of punch diameter and laminate thickness on the penetration behavior are investigated, and non-dimensional parameters introduced to reduce the number of independent variables. Post-mortem characterization of damage zones is used to identify the penetration mechanism in both systems.

\section{Materials and properties}

\subsection{Materials}

The study has investigated the Q.S. penetration of four fiber-reinforced and two solid state tapereinforced cross-ply $\left(0^{\circ} / 90^{\circ}\right)$ UHMWPE laminates, Table 1 . The study focused upon the response of

Dyneema ${ }^{\circledR}$ fiber-reinforced grades HB26 and HB50 and the Tensylon ${ }^{\circledR}$ tape-reinforced grade HSBD30A since the supply of Dyneema ${ }^{\circledR}$ HB2 12 was limited and assembly of a $\left[0^{\circ} / 90^{\circ}\right]$ tape based laminate, referred to here as BT10m, from woven Dyneema ${ }^{\circledR}$ BT10 (using the method developed in reference [6]) was time intensive. HB26 and HB50 have $\sim 83 \%$ of their mass reinforced by Dyneema ${ }^{\circledR}$ SK76 fibers and have similar ply thicknesses. HB50 used a weaker, but more compliant rubber-modified Kraton matrix (SISTC) while HB26 used a polyurethane matrix (PADP). The properties of these two materials have been extensively studied $[19,20,6,21,18,22]$. HB212 used the same matrix as HB50, but was reinforced with a stronger fiber and had thinner plies. The tape-reinforced grade HSBD30A contained an unknown resin, in low mass fraction, 
between plies. The fiber-reinforced grades were provided as $\left[0^{\circ} / 90^{\circ}\right]_{2}$ pre-pregs, while HSBD30A was provided as a $\left[0^{\circ} / 90^{\circ}\right]$ pre-preg. Laminated $\left[0^{\circ} / 90^{\circ}\right]_{\mathrm{n}}$ plates were formed by hot-pressing stacks of pre-preg using the procedure reported in [18] using a pressure of 20.6 MPa. The pressing temperature for the fiberreinforced grades was $127^{\circ} \mathrm{C}$, while $\mathrm{BT} 10 \mathrm{~m}$ used $130^{\circ} \mathrm{C}$ and $\mathrm{HSB} 30 \mathrm{~A} 105^{\circ} \mathrm{C}$ (as recommended by the suppliers of the materials). Square samples were cut on a band saw while clamped between $6.35 \mathrm{~mm}$ thick $\mathrm{Al}$ plates.

\subsection{Properties}

Attwood et al. [17] showed that the compressive behavior of a polymer fiber reinforced laminate is controlled by the quasi-static tensile strength of a ply and the inter-laminar shear strength. These two parameters were therefore measured using laminate tension and inter-laminar shear tests using procedures described in [18]. The through-thickness compressive strength of each laminate grade was also measured using the procedure from [18]. Representative loading responses for each material type are shown in Fig. 2. Table 1 summarizes the average tensile and shear strengths from five tests. The unidirectional ply tensile strength was taken to be twice the measured $\left[0^{\circ} / 90^{\circ}\right]_{4}$ laminate's tensile strength. Examination of Table 1 indicates that HB26 and HB50 have similar tensile strengths, $\sigma_{f}$, consistent with utilization of the same fiber, while HB26 had a shear strength, $\tau_{0}$ that was five times that of HB50. The shear strength of HB50 and HB212 were similar but HB212 a tensile strength that was 1.5 times that of HB50. The two tape-reinforced materials had similar tensile strengths of $1.2 \mathrm{GPa}$ (substantially lower than the fiber systems), and shear strengths approximately ten times that of HB50.

The through-thickness, uniform compression strength, $\sigma_{c}$, varies with in-plane sample length, $L$, because of the shear lag mechanism at the sample edges [17]. Square $1 \mathrm{~mm}$ thick samples used an in-plane length $L=6$ to $15 \mathrm{~mm}$, while 240 ply thick samples had $L=20$ and $25 \mathrm{~mm}$. The compressive strength (average of five tests) monotonically increased with increasing in-plane sample length, $L$, as the fraction of the loaded area within the shear lag region decreased, Fig. 3. At $L=25 \mathrm{~mm}$, the strengths of all the material grades were within $0.4 \mathrm{GPa}$ of each other. HB212 had the highest compressive strength, consistent with the 
material properties in Table 1 and the indirect tension model [23]. This data suggests that, if penetration resistance is governed by indirect tensioning of the plies, HB212 should have the greatest resistance.

\section{Methodology}

The samples prepared for the Q.S. penetration study were $100 \mathrm{~mm}$ (long) x $100 \mathrm{~mm}$ (wide) $\mathrm{x} H_{0} \mathrm{~mm}$ (thick), with $H_{0}$ values of 3, 6, 12, 18 and $24 \mathrm{~mm}$. Each sample was supported on an $18 \mathrm{~mm}$ thick, hardened A2 steel plate, Fig. 4. A picture frame, containing a $70 \mathrm{~mm}$ x $70 \mathrm{~mm}$ cutout was centrally located over the sample, and lightly clamped to prevent movement of the laminate during the test. A hardened A2 steel, flatbottomed, right-circular cylindrical (RCC) punch then loaded the center of the sample. The loading end of the punch measured either $6.35 \mathrm{~mm}$ or $12.7 \mathrm{~mm}$ in diameter, $d_{p}$, with the uniform portion of the cross-section extending $25.4 \mathrm{~mm}$ in length. The perimeter of the flat punch bottom had a radius of $1.5 \mathrm{~mm}$ to minimize stress concentration. An Instron (Pleasanton, CA, USA) model 4208 mechanical testing machine equipped with a $300 \mathrm{kN}$ load cell pressed the punch into a sample at a constant rate of displacement. No lubrication was applied to the punch. A global coordinate system was chosen with the $X$-axis aligned with the outermost ply (selected to be the $0^{\circ}$ ply), the $Z$-axis was parallel to the loading direction, and the origin was located where the center-line of the punch intersected the initial punch-sample interface, Fig. 4. The Q.S. indentation pressure, $\sigma=P / A_{p}$, where $P$ is the load and $A_{p}=\pi d_{p}^{2} / 4$ is the loading area of the punch. A laser extensometer measured the $Z$-displacement between two laser tags, one attached to the punch and the other to the platen,

Fig. 4. The measured punch displacement was taken to be the laminate indentation depth, $h$.

In-situ digital image correlation (DIC) was provided three-dimensional displacement measurement, $u_{x}, u_{y}$ and $u_{z}$, over the surface of $H_{0}=6 \mathrm{~mm}$ thick samples. Since the DIC system tracks the displacement of a speckle pattern, the $X-Y$ surface (normal to the load direction) was first spray painted white followed by the application of a stochastic pattern of $0.5 \mathrm{~mm}$ diameter black dots that covered approximately $50 \%$ of the surface area. A pair of 5 MP CCD cameras was positioned in a stereo configuration to capture the speckle pattern coated surface. The images were analyzed using Aramis v.6.3 (GOM mbH; Braunschweig, Germany) 3D image correlation software. The stochastic pattern was also applied to a portion of the punch surface that did not enter the laminate. This aided in alignment of the coordinate system during analysis and independent 
assessment of extensometer measurements of $h$. The central cross section plane of tested samples were examined by optical microscopy. X-ray computed tomography (XCT) also provided a non-destructive means for examination of the interior of a sample after testing. An Xradia (Pleasanton, CA, USA) model $\mu$ XCT-200 instrument probed a spherical volume, $6.8 \mathrm{~mm}$ in diameter, with a $6.75 \mu \mathrm{m}$ voxel size.

\section{Results}

\subsection{Load response}

The typical Q.S. indentation pressure verses penetration depth response of an $H_{0}=6 \mathrm{~mm}$ thick, HB26 laminate loaded by a $d_{p}=6.35 \mathrm{~mm}$ diameter RCC punch at $10 \mathrm{~mm} \mathrm{~min}^{-1}$ is shown by the long dashed line in Fig. 5(a). The pressure non-linearly increased with the indentation depth, $h$, until reaching a failure pressure, $\sigma_{p}=1.9 \mathrm{GPa}$ after $h=1.8 \mathrm{~mm}$ of indentation. Failure was highly energetic, accompanied by a $90 \%$ drop in load, a large acoustic emission and abrupt bulging of the laminate surrounding the punch. With further indentation, the load again increased and reached a pressure $\sigma_{p}=1.6 \mathrm{GPa}$ before a second failure. This cycle of repeated failure with further penetration resulted in a "saw-tooth" shaped pressure-displacement plot, similar to the observations on the Q.S. penetration of rear supported cross-ply UHWMPE laminates by Scott and Cheeseman [23] and Cain and Gaviola [24].

The $\sigma-h$ for the tape-reinforced laminate HSBD30A and the lower strength matrix HB50 samples are shown in Figs. 5(b) and (c), respectively. Again, the responses were saw-tooth in shape. The work, $W=O h P(h) \mathrm{d} h$, is plotted as a function of $h$ for the three laminates in Fig. 5(d)-(f). The tape grade HSBD30A required the greatest amount of work, $W=150 \mathrm{~J}$, for the punch to penetrate $h=5.5 \mathrm{~mm}$. The effect of using penetration rates of 1 and $90 \mathrm{~mm} \mathrm{~min}^{-1}$ are also shown on Figure 5. The HB26 and HSBD30A materials showed little loading rate sensitivity, Fig. 5(d) and (e). The HB50 material, however, failed at lower $\sigma_{p}$ values and required less work for penetration when tested at the slowest rate of $1 \mathrm{~mm} \mathrm{~min}^{-1}$, Fig. 5(c) and (f). This result is consistent with plastic (creep) deformation during the loading of this low shear strength laminate and is not addressed in this paper. All subsequent experiments with the $d_{p}=6.35 \mathrm{~mm}$ punch were performed at 10 $\mathrm{mm} \min ^{-1}$ unless otherwise stated. 
The effects of laminate thickness, $H_{0}$, and punch diameter, $d_{p}$, on the initial loading response of HB26 are shown in Fig. 6(a). Non-dimensional parameters are used for the initial sample thickness, $H_{0}{ }^{*}$, and indentation depth, $h^{*}$, as follows:

$$
\begin{aligned}
& H_{0}{ }^{*}=H_{0} / d_{p} \\
& h^{*}=h / d_{p}
\end{aligned}
$$

The scaling factor $d_{p}^{-1}$ was motivated by the contact pressure relationship for a non-deformable RCC punch indenting a homogenous, linear-elastic solid, where $\sigma=(4 E \star / \pi)(h / d p)[25]$. While tests using the $d_{p}$ $=6.35 \mathrm{~mm}$ punch (black lines) show the compliance increased with laminate thickness, laminates having the same $H_{0}{ }^{*}$ value but tested with different punch diameters (compare black and grey lines for either $H_{0} * \approx 1$ or 2) had a similar response. $H_{0} *$ is therefore an appropriate non-dimensional form of the laminate thickness.

The thickness of the remaining laminate between the punch and the platen was defined by a third non-dimensional parameter:

$$
H *=H O *-h *
$$

When $\left(H_{0}^{*} \approx 1\right)$ laminates were tested with a punch of $d_{p}=6.35$ or $12.7 \mathrm{~mm}$, the $\sigma-H^{*}$ responses $^{1}$ overlapped, with similar periodicity between failure events and similar failure pressures, $\sigma_{p}$, Fig. 6(b). The same observations held when testing various $H_{0} *$ thickness laminates with a punch of $d_{p}=6.35$, Fig. 6(c)-(d). Hence, the parameter $H^{*}$ provided an appropriate means to scale and align sample responses. This indicates that pressure was not coupled to the initial laminate thickness, i.e. the perforated plies closest to the punch did not provide confinement or add friction. We also note the $\sigma_{p}$ values decreased with $H^{*}$ once the plate was sufficiently "thin" $\left(H^{*} \approx 0.5\right)$ for the proximity to the stiffer foundation to influence the response.

\footnotetext{
${ }^{1}$ Note the punch depth goes from right to left when using $H^{*}$ as the independent variable.
} 
Non-dimensional parameters can be also used to collapse the work verses indentation depth responses of the various materials. We first defined a specific work parameter:

$$
W *=-H O * H * \sigma \mathrm{d} H *=O h * \sigma \mathrm{d} h *=W /(\mathrm{dp} A p)
$$

This uses the scaling factor $d_{p}{ }^{-1}$ to normalize the displacement and the load is divided by the loading area, $A_{p}$. The remaining work for complete penetration is then given by:

$$
R *=W t o t *-W *
$$

where $W t o t *=W \star($ as $H \star \rightarrow 0)$ is the total work to fully penetrate the laminate. Fig. 7(a) plots $R^{*}$ as a function of $H^{*}$ for HB26 with four different $H_{0}{ }^{*}$ values. The curves collapse to a single response, where $R^{*}$ monotonically increased with $H^{*}$. Only a minor horizontal deviation of $R^{*}$ was present as $H^{*}$ approached $H_{0}{ }^{*}$, which results from the initial non-linear loading compliance previously seen in Fig. 6(a). Therefore, the total work to fully penetrate a laminate of an arbitrary thickness can be adequately estimated from the $R^{*}$ versus $H^{*}$ response obtained from a thicker laminate of the same grade.

Fig. 7(b) plots the $R^{*}$ versus $H^{*}$ responses for the five laminate materials whose properties are summarized in Table 1 . They had an initial thickness, $H_{0} * \approx 3$ and were quasi-statically penetrated to a depth $H^{*}=0.18$. Four of the materials (HB26, HB50, BT10m and HSBD30A) required $R^{*} \sim 2.5 \mathrm{~J} \mathrm{~m}^{-3}$ to fully penetrate the laminates. These results are consistent with tape-reinforced materials exhibiting similar ballistic resistance to the higher tensile strength fiber-reinforced grades in rear supported test conditions [8]. However, the HB212 material required $\sim 3.7 \mathrm{~J} \mathrm{~m}^{-3}$ for full penetration (approximately $50 \%$ more work than the other four grades). As the energy absorbed in quasi-static and dynamic penetration are similar (when the possibility of deflection is eliminated) [8], HB212 should provide superior deep penetration resistance compared to the other four laminates.

The mean indentation pressure, $\sigma_{a}$, of each material (i.e. the $R^{*}-H^{*}$ slope) is plotted against its uniform compressive strength, $\sigma_{c}(L=25 \mathrm{~mm})$, in Fig. 7(c). The mean pressure increased linearly with 
compressive strength, with a $\sigma_{a}: \sigma_{c}$ ratio of 2 . A higher ratio of 3-5 is commonly observed in ductile metals, where the pressure enhancement over the uniaxial strength arises from self-confinement by the material surrounding the punch [26]. These laminates provide less confinement than metals, as exemplified by the severity of free surface bulging and by the material damage adjacent to the punch; to be discussed subsequently in Section 4.2 .

\subsection{Deformation and failure}

Fig. 8(a) shows the indented surface of an $H_{0} * \approx 1$, HB50 sample just prior to the initial failure (first load drop). A false color rendering of the DIC determined Z-component displacement, $u_{z}$, is overlaid on the image. The penetration of the punch caused a lifting of surrounding material immediately adjacent to the punch resulting in crater formation. A smaller cross-shaped region of out of plane displacement is also apparent. Each arm of the cross shape was oriented in a fiber direction and had a similar width to that of the punch. The magnitude of the displacement increased towards the centerline of each arm of the cross.

The $u_{z}$ deformation along the $Y=0$ section to the right of the punch (see Fig. 8(a)) is plotted versus X-position in Fig. 8(b). The first $h=0.3 \mathrm{~mm}$ of punch displacement compressed the laminate along the entire profile, with the greatest compression nearest the punch. After $h=0.86 \mathrm{~mm}$, material near the punch started to bulge away from the laminate interior. The bulge height ( $Z$-oriented) and width $(X$-oriented) increased with punch displacement. The source of some of the bulged material originated from $X$-oriented pull-in from the edges, Fig. 8(c). The gradient in the $u_{x}-X$ graph also revealed tensile straining of the outermost fibers. The strain increased from $\sim 0.1 \%$ to $0.3 \%$ as $h$ increased from 0.3 to $1.5 \mathrm{~mm}$. For the higher shear strength HB26 laminate, a bulge also developed adjacent to the punch but with a smaller height and width than in HB50. In contrast to the fiber grades, the tape grade HSBD30A compressed further with increased penetration depth, Fig. 8(d).

A $Y-Z(X=0 \mathrm{~mm}) \mu$-XCT cross-sectional image from an HB26 sample after loading to half of its initial failure load is shown in Fig. 9(a). A high concentration of elongated voids (air is rendered dark grey in these reconstructions) near the periphery of the punch can be seen. The voids are present only in the $0^{\circ}$ plies, 
whose fibers were in the X-direction, and their severity decreased with depth from the outer surface. The voids corresponded to regions of local ply thinning consistent with fibers under the punch being displaced in the Y-direction (transversely to the fibers). A similar voided region developed near the sides of uniform compressed samples, where the through thickness compression had activated transverse Poisson expansion of the ply, Fig. 1. While the fibers under uniform compression were extruded from the cut sides of the samples, the fibers here were forced into the non-compressed laminate region adjacent to that compression by the punch, and contributed to the bulging observed in Fig. 8(a).

An optical micrograph of an $H_{0} * \approx 0.5$, HB50 laminate after initial failure is shown in Fig. 10(a). The punch left a cylindrical shaped hole, with the same width as the punch diameter. To the sides of the indent, the laminate had bulged in the Z-direction. This region contained 27 plies, which had all fractured and buckled, Fig. 10(c). However, the plies below the bottom of the punch were intact. A ballistic impact study on HB50 previously showed that a projectile impact resulted in similar fiber failure and bulging behavior [8]. The observations are consistent with the fibers directly beneath the projectile having failed in tension. This released the stored elastic strain energy and caused the plies to recoil into the surrounding volume where they buckled upon themselves. The laminate then bulged to accommodate the volume occupied by the buckled plies.

A micrograph of an $H_{0} * \approx 0.5, \mathrm{HB} 50$ laminate after a second failure event is shown in Fig. 10(b). Both the depth of the cylindrical crater and the bulging from the front face were greater. In contrast to the first failure event resulting in the failure of the plies closest to the punch, a group of $\sim 12$ plies located in the region between the bottom of the crater and the rear face had failed, Fig. 10(d). These plies similarly buckled and recoiled into the surrounding laminate, which caused bulging of the nearby rear face. The laminate was within the "thin" laminate regime discussed above (Fig. 5), with $H^{*}=0.2$ as the second failure event occurred. Fig. 10(e) shows the $H_{0} * \approx 0.5$ tape grade HSB30A which failed in a similar manner to HB50, Fig. 10(b). Examined after two failure events, plies had failed both directly below the punch and between the bottom of the crater and the rear face. Again, this laminate was within the thin laminate regime. 
A $\mu$-XCT image of the upper bulge region of an HSB30A sample loaded to half its failure pressure is shown in Fig. 9(b). In contrast to the HB26 sample, Fig. 9(a), no ply thinning was apparent below the edge of the punch and the damage was not as deep. One delamination plane extended to the edge of the sample and allowed for the pull-in of material to accommodate the permanent bulge to the side of the punch loading area. The lower amount of permanent deformation observed with the HSBD30A grade compared to HB26 is consistent with the uniform compression behavior, where the fiber grades are governed by the shear strength while the tape grades remain elastic.

\section{Discussion and concluding remarks}

The three UHWMPE fiber and two UHWMPE tape reinforced cross-ply laminates progressively failed when placed on a hard foundation and quasi-statically pressed with the flat end of a hard right circular cylinder. Highly energetic, but subcritical failure events with substantial drops in load resulted in a 'sawtooth' shaped load-displacement profile as the indentation depth was monotonically increased. The penetration behavior was shown to scale with the ratio of the thickness of the remaining laminate, $H$, to the diameter of the punch, $d_{p}$, (independent of the original laminate thickness).

For thick laminates (those with an intact remaining thickness greater than the punch radius), optical and XCT observations revealed that the reinforcement closest to the punch failed, Fig. 8-10, similar to the damage resulting from ballistic impacts on UHMWPE laminates $[3,8]$. The mean indentation pressure, $\sigma_{a}$, also showed a strong dependence upon the compressive strength for a large in-plane dimension samples, Fig. 9. Furthermore, the maximum $\sigma_{p}$ value of $\sim 1.8 \mathrm{GPa}$ reached by both HB26 and HB50 is the intrinsic compressive strength for both materials, Fig. 5, as predicted by the indirect tension model [18]. These observations are consistent with tensile rupture of the reinforcement by indirect tension. No evidence of shear

plug formation was observed for any of the grades, in contrast to observations of carbon- and glass-reinforced composites, which use much stiffer matrices [10-15].

To summarize the mechanism of laminate response, Fig. 11 shows a schematic illustration of the $Y-Z$ cross-sectional plane of a punch compressing the laminate material below the loading area. For the range of 
punch diameter, ply thickness and laminate width studied here, the anisotropic Poisson expansion of the ply in response to the compressive stress activates the shear lag mechanism at the edge of the loading area. This mechanism converts the out of plane compressive stress into a resultant tensile stress in each ply's reinforcement direction. The tensile stress then increases with indentation depth (pressure) until the ply tensile strength is reached. Consistent with the compressive stress in a semi-infinite body being greatest nearest the punch [25], the failure strength was first reached in the group of plies closest to the punch for thick laminates. For thin laminates, the stress distribution in the laminate was affected by its proximity to the stiff supporting foundation, changing the location of indirect tensile failure, and decreasing the peak pressure.

Scaling arguments were also introduced for the work to quasi-statically penetrate the laminate. Previous studies have shown the impact resistance of UHMPWE laminates scales with the Q.S. penetration resistance $[8,24]$. Two fiber reinforced laminates with similar tensile strengths, but different shear strengths required a similar work of penetration. This Q.S. penetration work was similar to that of two tape-based systems whose plies had a substantially lower tensile strength than that of the two fiber systems but a similar out of plane compressive strength. This result is fully consistent with tape-reinforced materials having similar ballistic resistance to the higher tensile strength fiber-reinforced grades in rear supported conditions [8]. Furthermore, the highest out of plane compressive strength laminate, HB212, required the most work to penetrate, suggesting it should provide superior ballistic absorbance over the other laminate grades when placed near the front of a laminate or when layered in a thick laminate. By Q.S. penetration of rear supported laminates, this study both identified the key failure mechanisms operating during laminate penetration and provided a simple method for ranking the penetration resistance of a laminate when its penetration is governed by indirect tensile failure.

\section{Acknowledgements}

We are grateful to DSM and DuPont for providing the materials used in this study. This research was funded by the Defense Advanced Research Projects Agency (DARPA) under grant number W91CRB-11-10005 (Program manager, Dr. J. Goldwasser). Dyneema ${ }^{\circledR}$ is a trademark of DSM. 


\section{References}

[1] Cheeseman BA, Bogetti TA. Ballistic impact into fabric and compliant composite laminates. Compos Struct 2003;61:161-73. doi:10.1016/S0263-8223(03)00029-1.

[2] Cunniff PM. Dimensionless parameters for optimization of textile-based body armor systems. In: Reinecke WG, editor. Proc. 18th Int. Symp. Ballist., San Antonio, TX: Technomic Publishing Company, Inc; 1999, p. 1303-10.

[3] O’Masta MR, Deshpande VS, Wadley HNG. Mechanisms of projectile penetration in Dyneema ${ }^{\circledR}$ encapsulated aluminum structures. Int J Impact Eng 2014;74:16-35. doi:10.1016/j.ijimpeng.2014.02.002.

[4] Karthikeyan K, Russell BP. Polyethylene ballistic laminates: Failure mechanics and interface effect. Mater Des 2014;63:115-25. doi:10.1016/j.matdes.2014.05.069.

[5] Nguyen LH, Ryan S, Cimpoeru SJ, Mouritz AP, Orifici AC. The effect of target thickness on the ballistic performance of ultra high molecular weight polyethylene composite. Int J Impact Eng 2015;75:174-83. doi:10.1016/j.ijimpeng.2014.07.008

[6] Karthikeyan K, Russell BP, Fleck NA, Wadley HNG, Deshpande VS. The effect of shear strength on the ballistic response of laminated composite plates. Eur J Mech - ASolids 2013;42:35-53. doi:10.1016/j.euromechsol.2013.04.002.

[7] Heisserer U, van der Werff H, Hendrix J. Ballistic Depth of Penetration Studies in Dyneema ${ }^{\circledR}$ Composites. In: Wickert M, Salk M, editors. Proc. 27th Int. Symp. Ballist., vol. 2, Freiburg, Germany: DEStech Publications, Inc.; 2013, p. 1936-43.

[8] O’Masta MR, Crayton DH, Deshpande VS, Wadley HNG. Mechanisms of penetration in polyethylene reinforced cross-ply laminates. Int J Impact Eng 2015;86:249-64. doi:10.1016/j.ijimpeng.2015.08.012. 
[9] Woodward RL, Egglestone GT, Baxter BJ, Challis K. Resistance to penetration and compression of fibre-reinforced composite materials. Compos Eng 1994;4:329-41. doi:10.1016/0961-9526(94)900833.

[10] Cantwell WJ, Morton J. Impact perforation of carbon fibre reinforced plastic. Compos Sci Technol 1990;38:119-41. doi:10.1016/0266-3538(90)90002-M.

[11] Culnane AH, Woodward RL, Egglestone GT. Failure examination of composite materials using standard metallographic techniques. J Mater Sci Lett 1991;10:333-4. doi:10.1007/BF00719700.

[12] Lee S-WR, Sun CT. Dynamic penetration of graphite/epoxy laminates impacted by a blunt-ended projectile. Compos Sci Technol 1993;49:369-80. doi:10.1016/0266-3538(93)90069-S.

[13] Gama BA, Gillespie Jr. JW. Punch shear based penetration model of ballistic impact of thick-section composites. Compos Struct 2008;86:356-69. doi:10.1016/j.compstruct.2007.11.001.

[14] Gama BA, Gillespie Jr. JW. Finite element modeling of impact, damage evolution and penetration of thick-section composites. Int J Impact Eng 2011;38:181-97. doi:10.1016/j.ijimpeng.2010.11.001.

[15] Shaktivesh, Nair NS, Sesha Kumar CV, Naik NK. Ballistic impact performance of composite targets. Mater Des 2013;51:833-46. doi:10.1016/j.matdes.2013.04.093.

[16] Manzella AF, Gama BA, Gillespie Jr. JW. Effect of punch and specimen dimensions on the confined compression behavior of S-2 glass/epoxy composites. Compos Struct 2011;93:1726-37. doi:10.1016/j.compstruct.2010.11.006.

[17] Attwood JP, Khaderi SN, Karthikeyan K, Fleck NA, O’Masta MR, Wadley HNG, et al. The out-ofplane compressive response of Dyneema ${ }^{\circledR}$ composites. J Mech Phys Solids 2014;70:200-26. doi:10.1016/j.jmps.2014.05.017. 
[18] O’Masta MR, Deshpande VS, Wadley HNG. Defect controlled transverse compressive strength of polyethylene fiber laminates. Int J Solids Struct 2015;52:130-49. doi:10.1016/j.ijsolstr.2014.09.023.

[19] Russell BP, Karthikeyan K, Deshpande VS, Fleck NA. The high strain rate response of Ultra High Molecular-weight Polyethylene: From fibre to laminate. Int J Impact Eng 2013;60:1-9. doi:10.1016/j.ijimpeng.2013.03.010.

[20] Karthikeyan K, Russell BP, Fleck NA, O’Masta MR, Wadley HNG, Deshpande VS. The soft impact response of composite laminate beams. Int J Impact Eng 2013;60:24-36. doi:10.1016/j.ijimpeng.2013.04.002.

[21] Liu G, Thouless MD, Deshpande VS, Fleck NA. Collapse of a composite beam made from ultra high molecular-weight polyethylene fibres. J Mech Phys Solids 2014;63:320-35. doi:10.1016/j.jmps.2013.08.021.

[22] Nazarian O, Zok FW. Constitutive model for the shear response of Dyneema ${ }^{\circledR}$ fiber composites. Compos Part Appl Sci Manuf 2014;66:73-81. doi:10.1016/j.compositesa.2014.06.012.

[23] Scott BR, Cheeseman BA. The Mechanics of Projectile Arrest for Compliant Cross Plied Unidirectional Laminates. In: Bless S, Walker J, editors. vol. Vol. 2, New Orleans, LA: DEStech Publications, Inc.; 2008, p. 992-1002.

[24] Cain J, Gaviola M. Investigation into the Material Properties and Penetration-resistant Behavior of UHMWPE Composites Using a Novel Test Methodology and Correlation with Ballistic Performance. Proc. SAMPE, Baltimore, MD: 2015.

[25] Fishcer-Cripps AC. Introduction to Contact Mechanics. Second Edition. New York: Springer; 2007.

[26] Bishop RF, Hill R, Mott NF. The theory of indentation and hardness tests. Proc Phys Soc 1945;57:14759. 
Table 1. Laminate properties and constituent materials

\begin{tabular}{|c|c|c|c|c|c|}
\hline & $\begin{array}{c}\text { Dyneema }^{\circledR} \\
\text { HB26 }\end{array}$ & $\begin{array}{c}\text { Dyneema }^{\circledR} \\
\text { HB50 }\end{array}$ & $\begin{array}{c}\text { Dyneema }^{\circledR} \\
\text { HB212 }\end{array}$ & $\begin{array}{l}\text { Dyneema }^{\circledR} \\
\text { BT10m }\end{array}$ & $\begin{array}{l}\text { Tensylon }^{\circledR} \\
\text { HSBD30A }\end{array}$ \\
\hline Manufacturer & DSM & DSM & DSM & DSM & DuPont \\
\hline Fiber Type & $\begin{array}{l}\text { Dyneema }^{\circledR} \\
\text { SK76 }\end{array}$ & $\begin{array}{l}\text { Dyneema }^{\circledR} \\
\text { SK76 }\end{array}$ & $\begin{array}{l}\text { Dyneema }^{\circledR} \\
\text { SK99 }\end{array}$ & N/A & $\mathrm{N} / \mathrm{A}$ \\
\hline $\operatorname{Resin}^{\mathrm{a}}$ & PADP & SISTC & SISTC & N/A & N/A \\
\hline $\begin{array}{l}\text { Fiber diameter/Tape } \\
\text { thickness }(\mu \mathrm{m})\end{array}$ & 17 & 17 & 10 & 42 & 56 \\
\hline $\begin{array}{l}\text { Ply thickness, } t \text {, } \\
(\mu \mathrm{m})\end{array}$ & 67 & 60 & 35 & 42 & 56 \\
\hline $\begin{array}{l}\text { Ply tensile strength, } \\
\sigma_{f}(\mathrm{GPa})\end{array}$ & 1.7 & 1.7 & 2.6 & 1.2 & 1.2 \\
\hline $\begin{array}{l}\text { Inter-laminar shear } \\
\text { strength, } \tau_{0}(\mathrm{MPa})\end{array}$ & 1.8 & 0.35 & 0.42 & 3.5 & 3.0 \\
\hline
\end{tabular}

${ }^{a}$ Resin abbreviations: polyetherdiol-aliphatic diiocyanate polyurethane (PADP); styreneisoprene-styrene triblock copolymer (SISTC) 


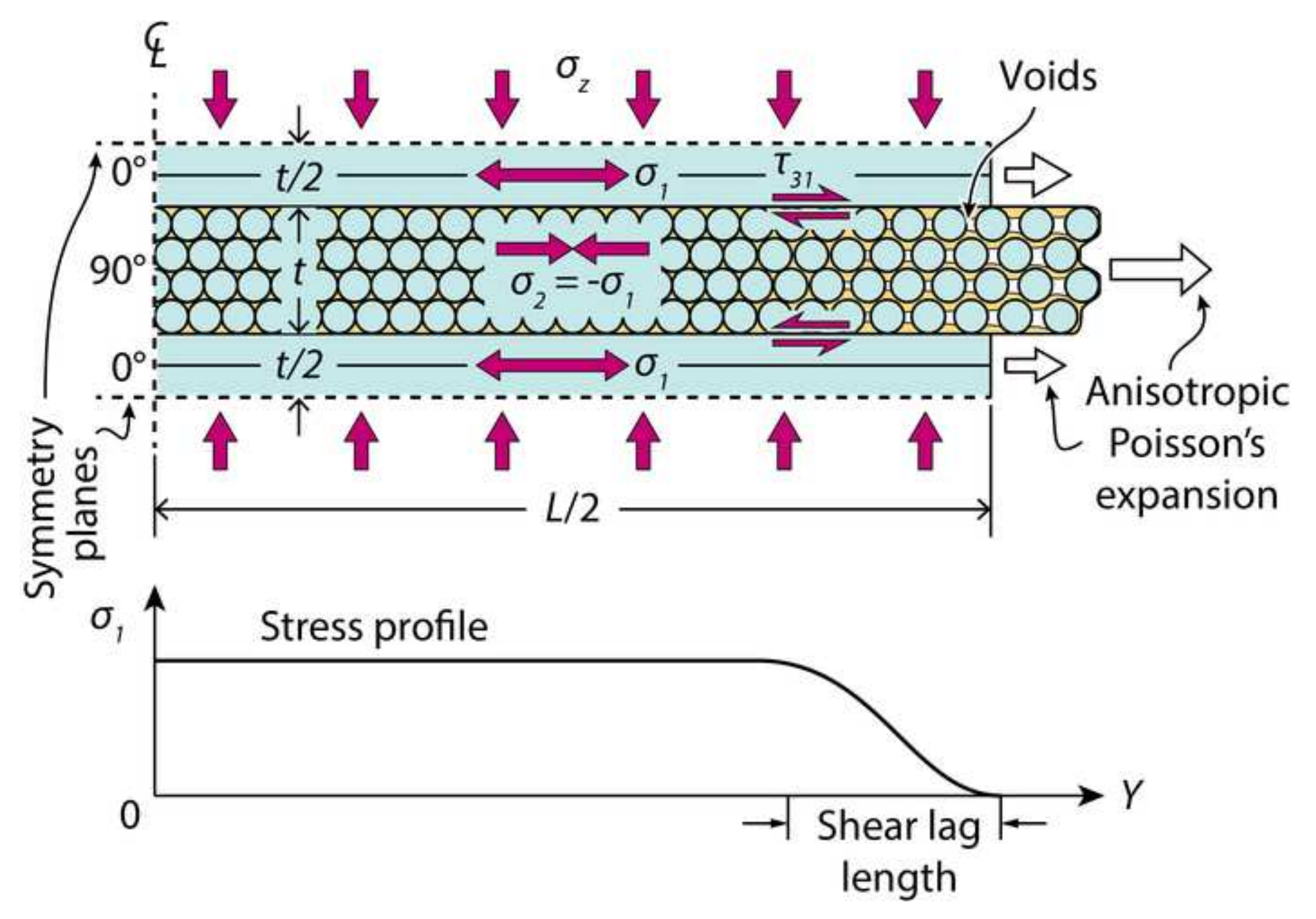


(a) Tension
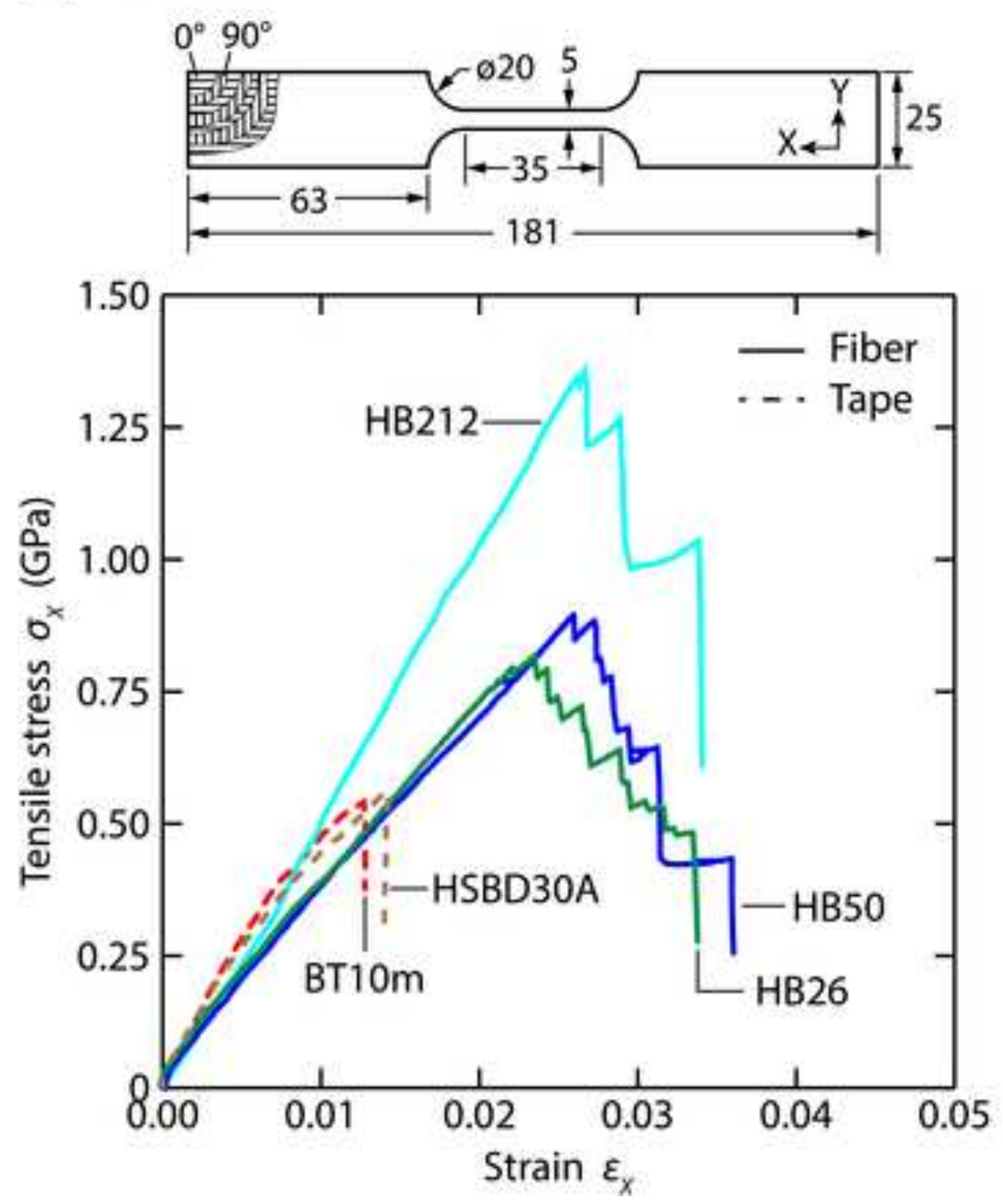

(b) Shear
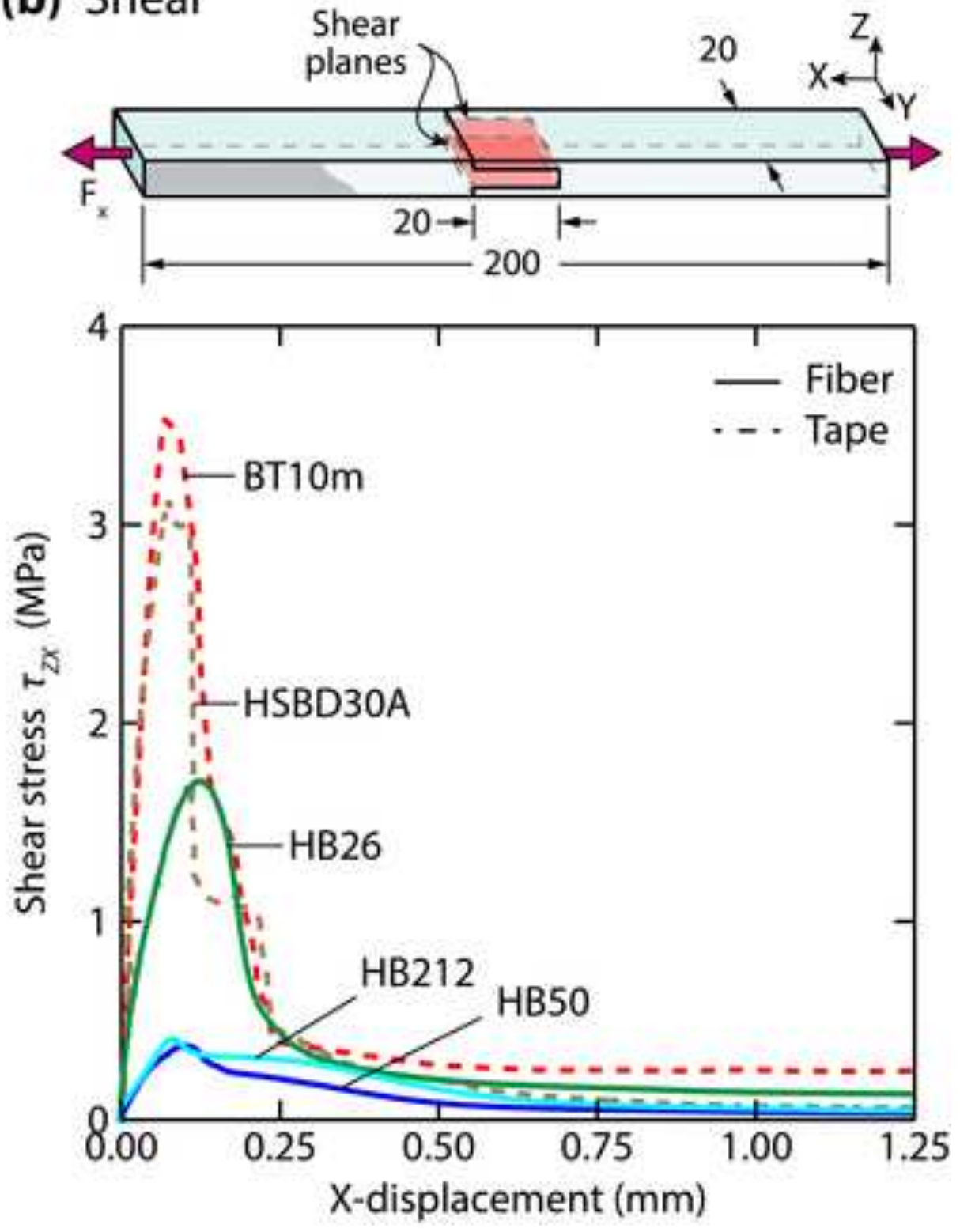


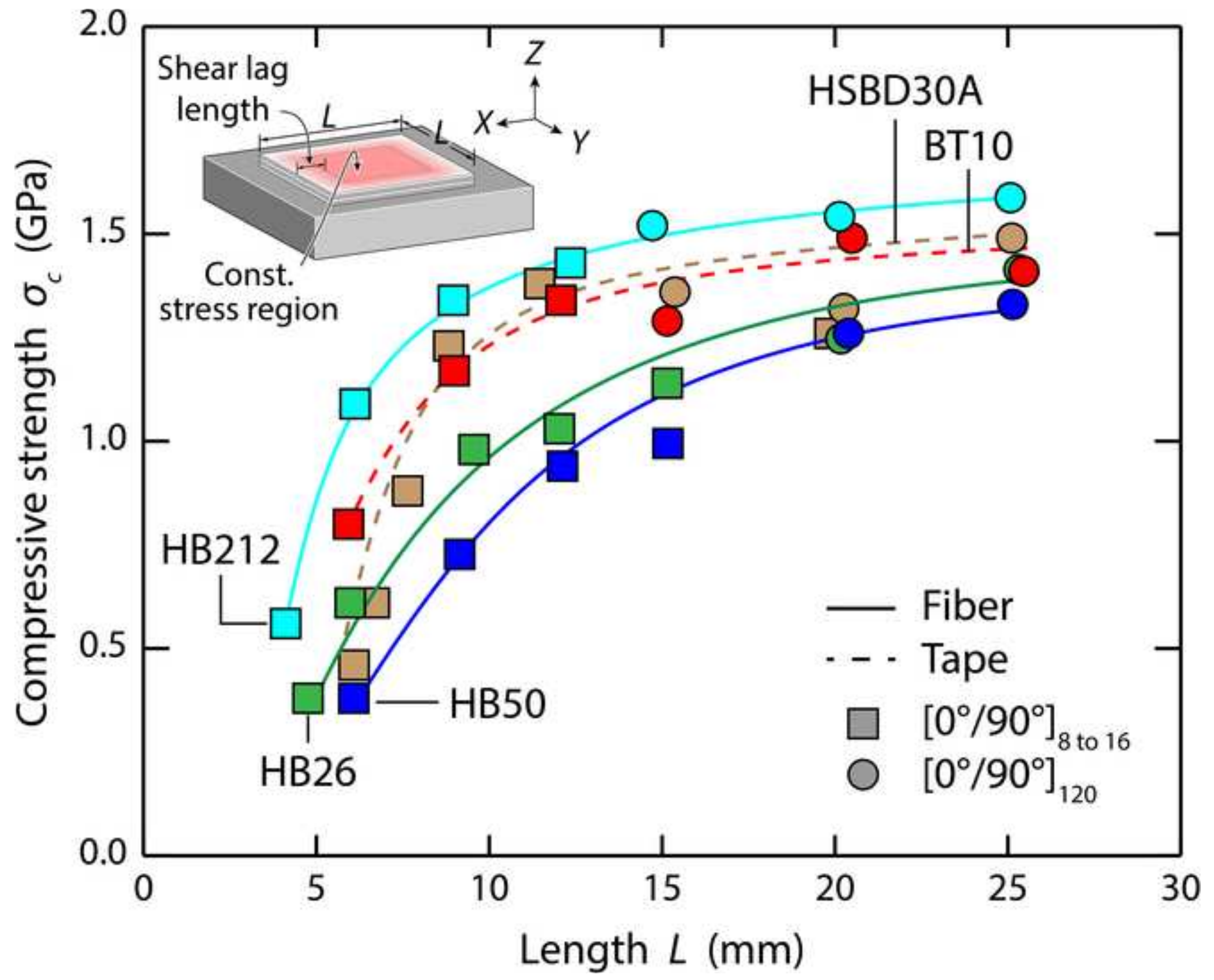




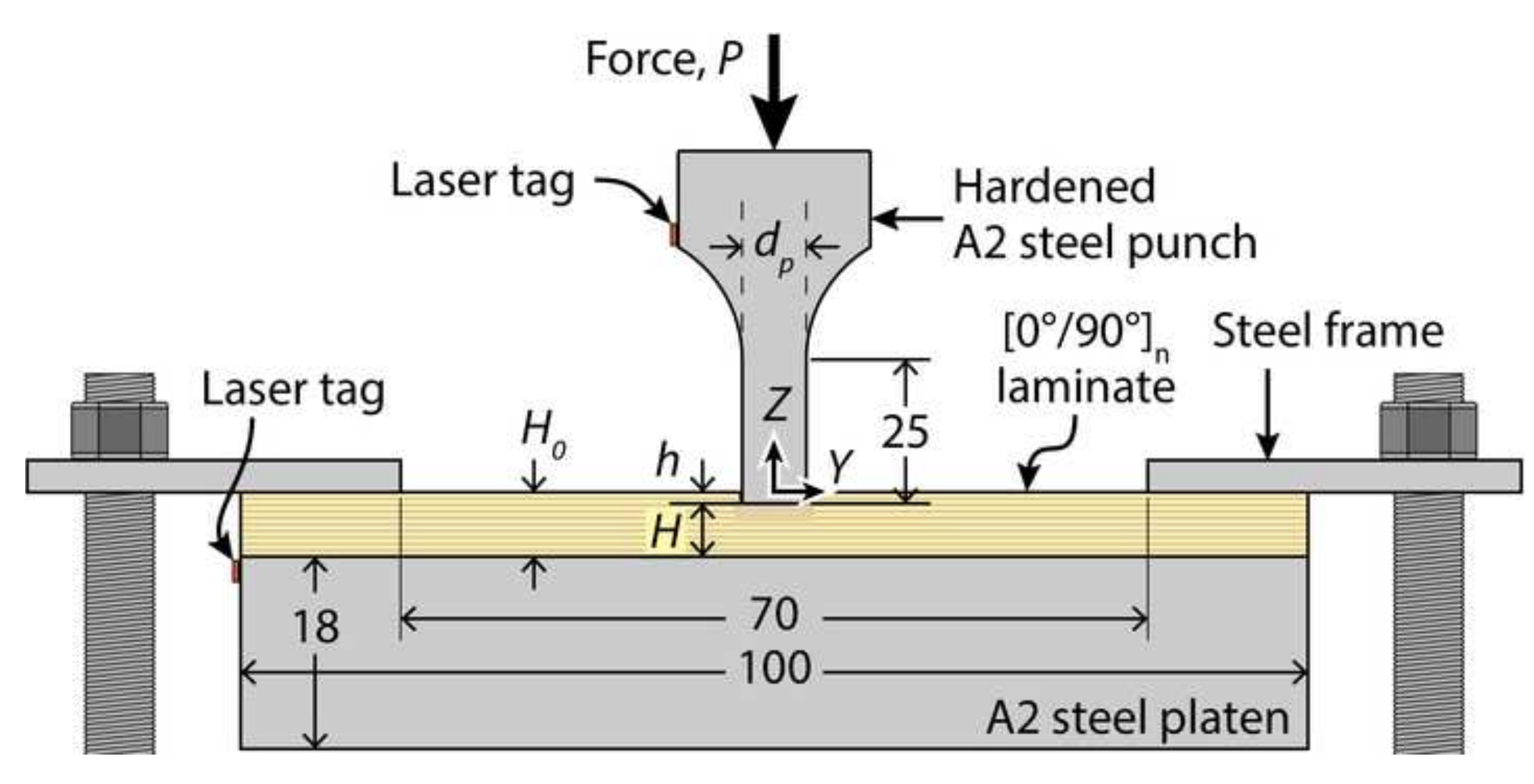

$\left[0^{\circ} / 90^{\circ}\right]_{n}$ Steel frame A2 steel platen 
(a) HB26, pressure-displacement

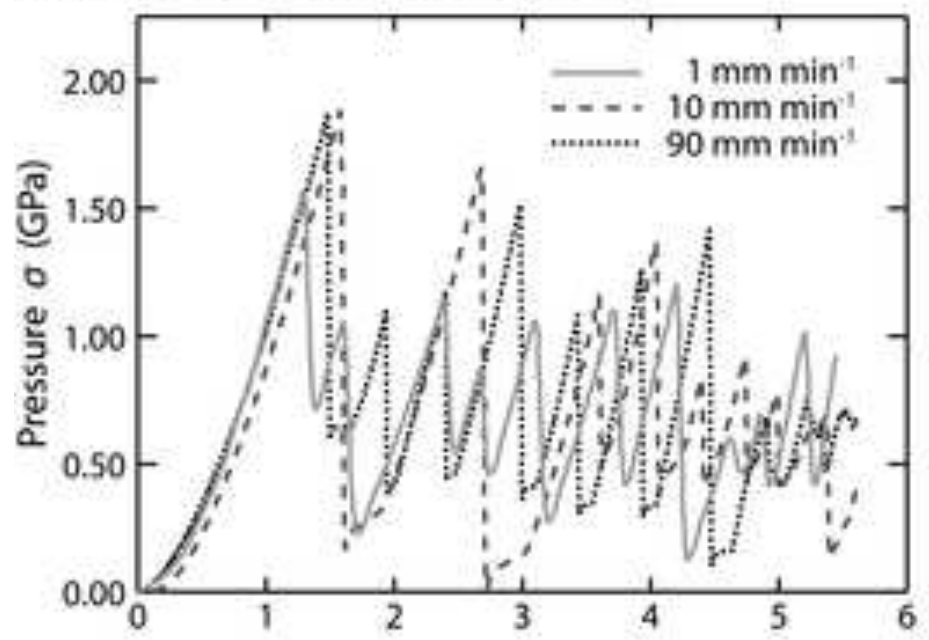

(b) HSBD30A, pressure-displacement

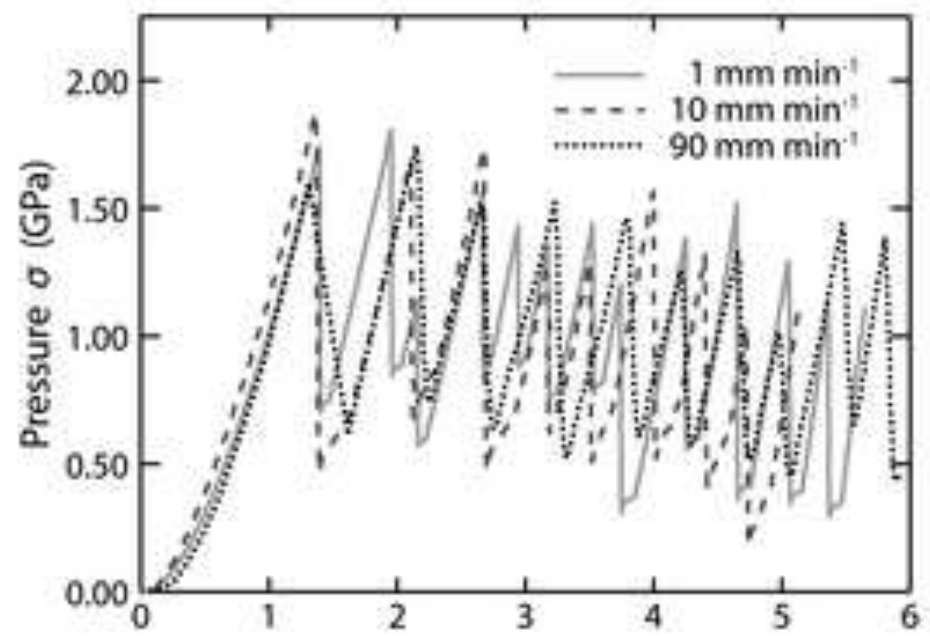

(c) HB50, pressure-displacement

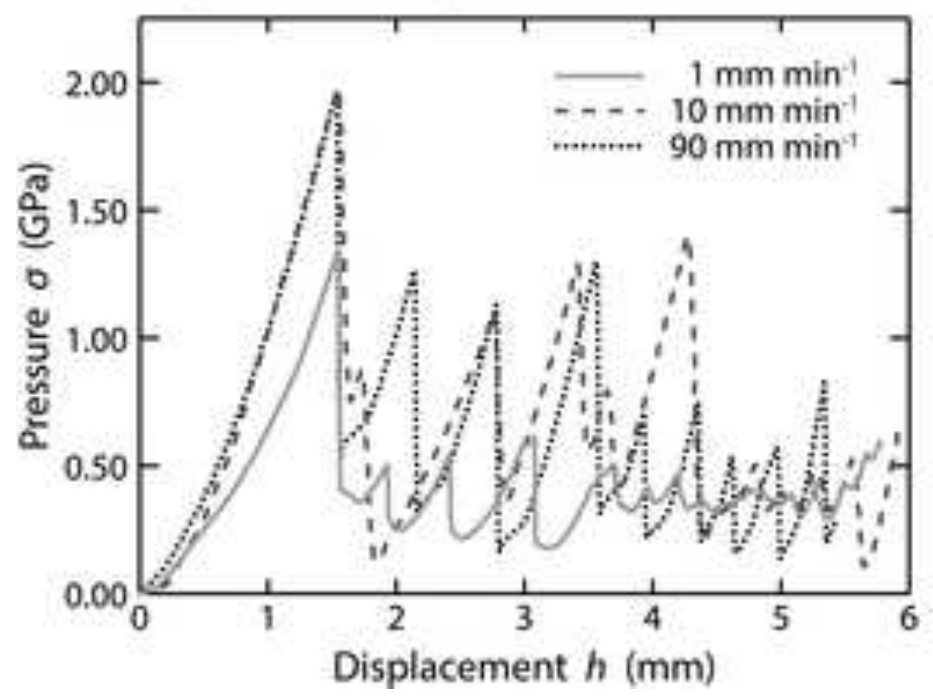

(d) HB26, work-displacement

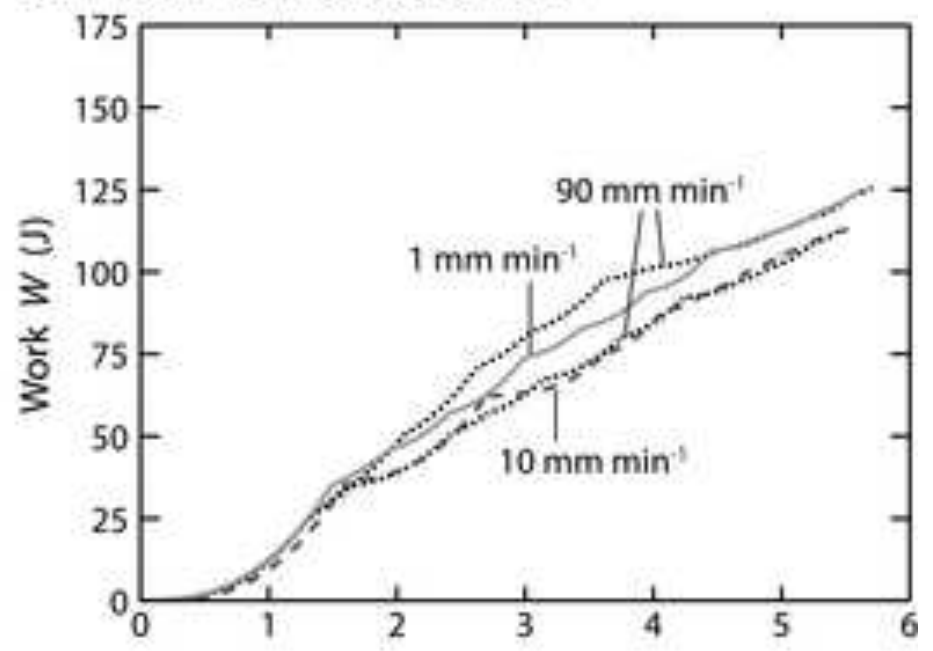

(e) HSBD30A, work-displacement

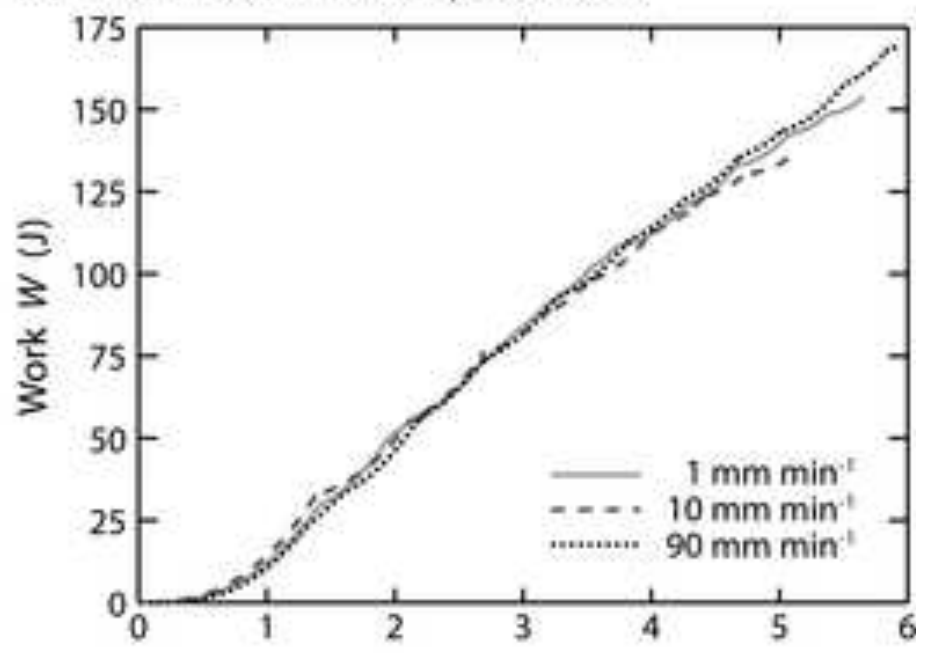

(f) $\mathrm{HB50}$, work-displacement

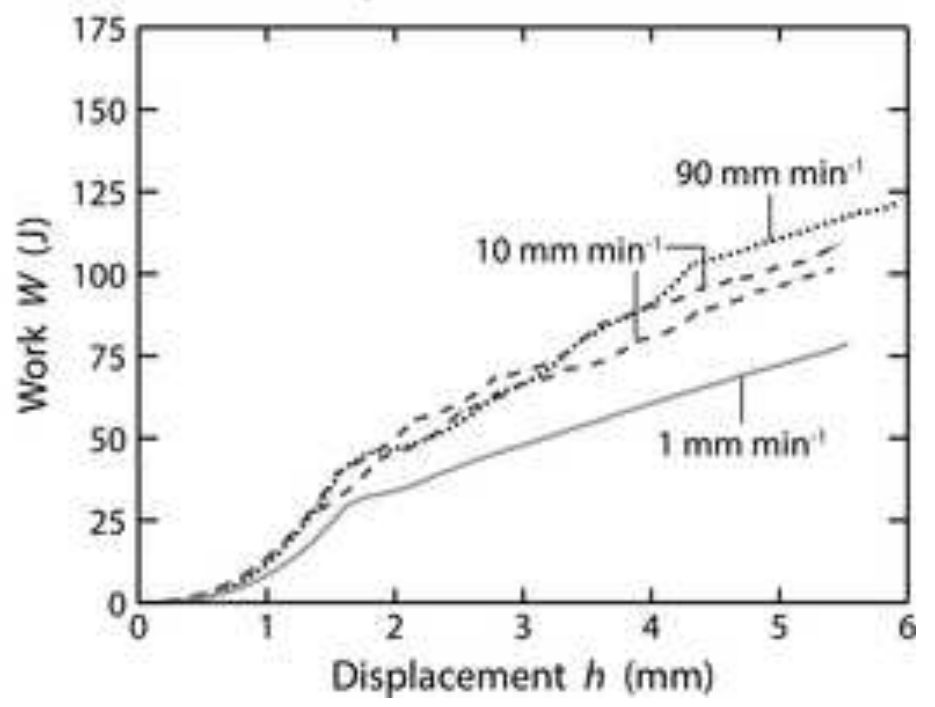


(a) $h^{*}$ normalization

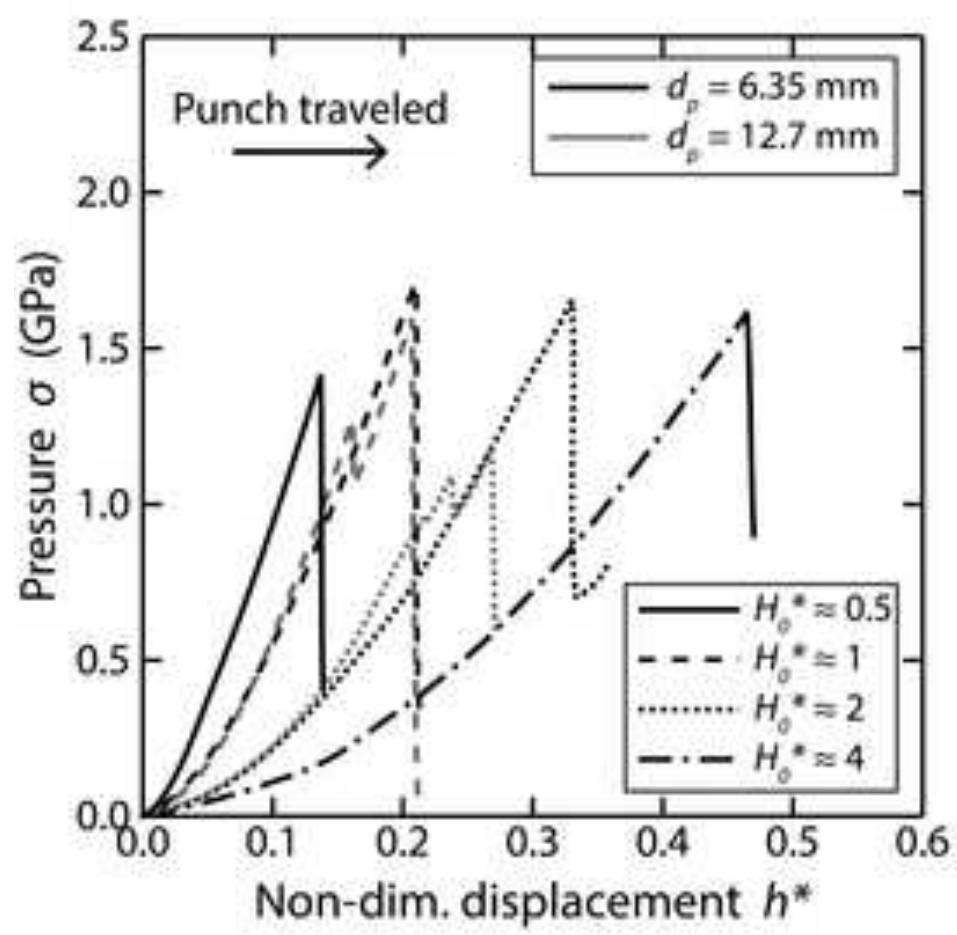

(c) $\mathrm{H}^{*}$ normalization; varying $\mathrm{H}_{0}{ }^{*}$

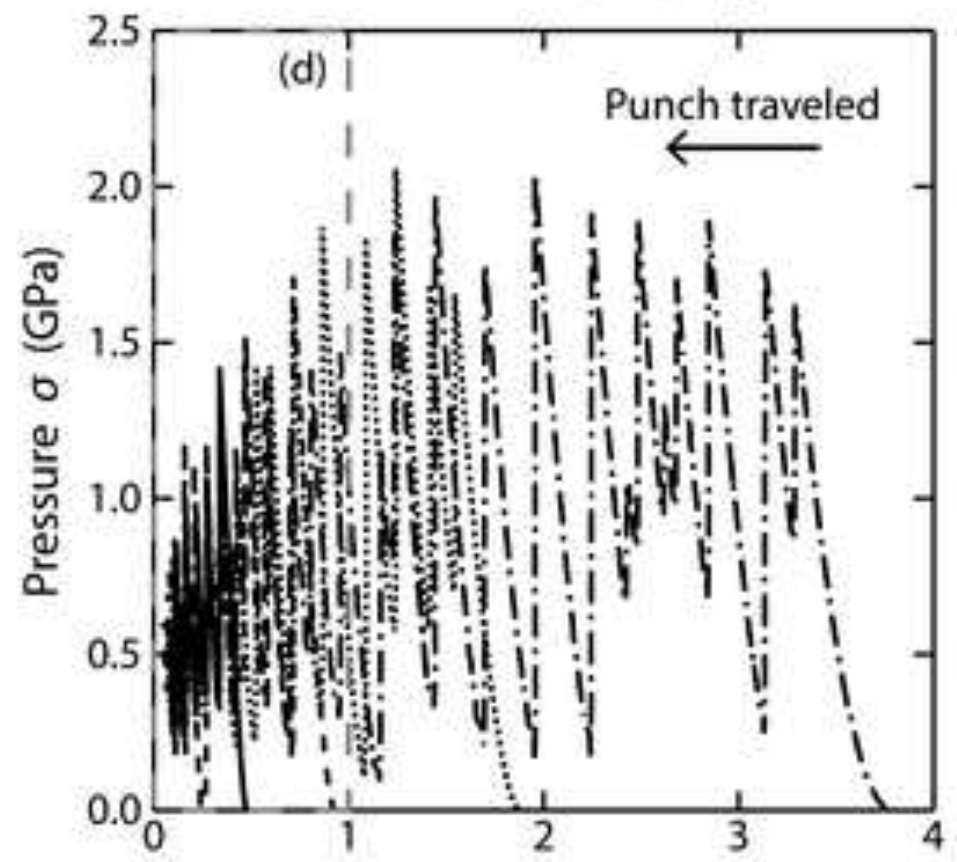

Non-dim. remaining thickness $H^{*}$ (b) $H^{*}$ normalization; $H_{0}{ }^{*} \approx 1$

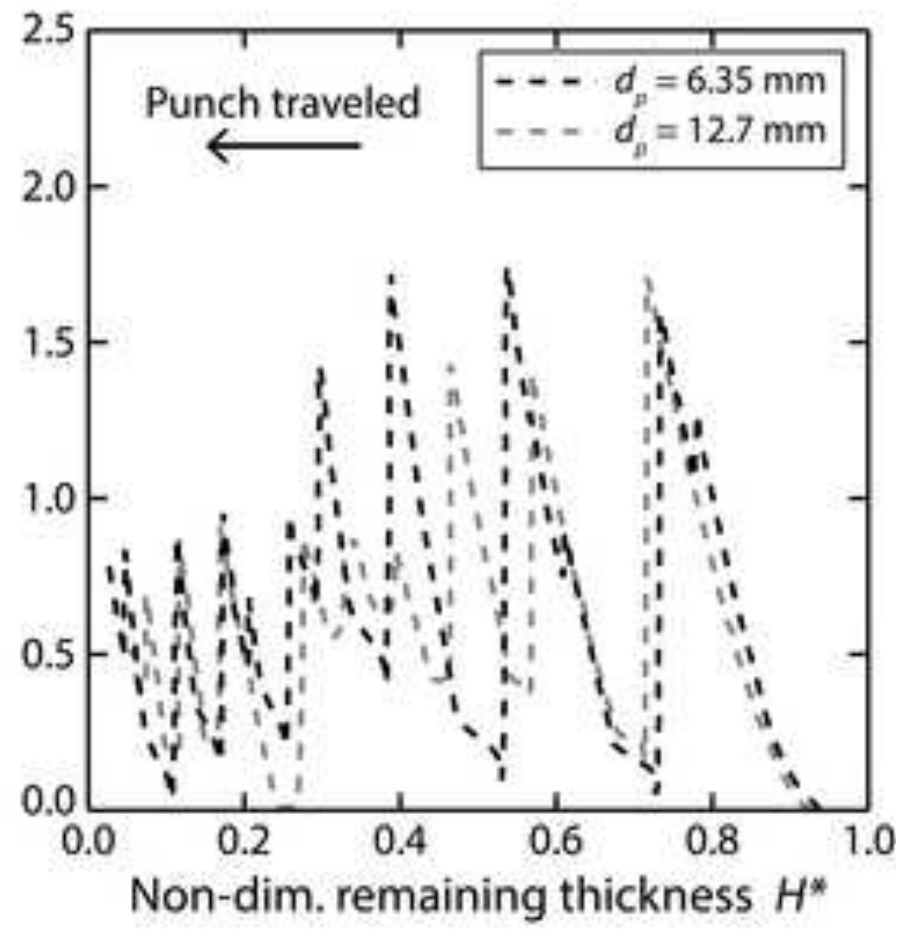

(d) Inset from (c)

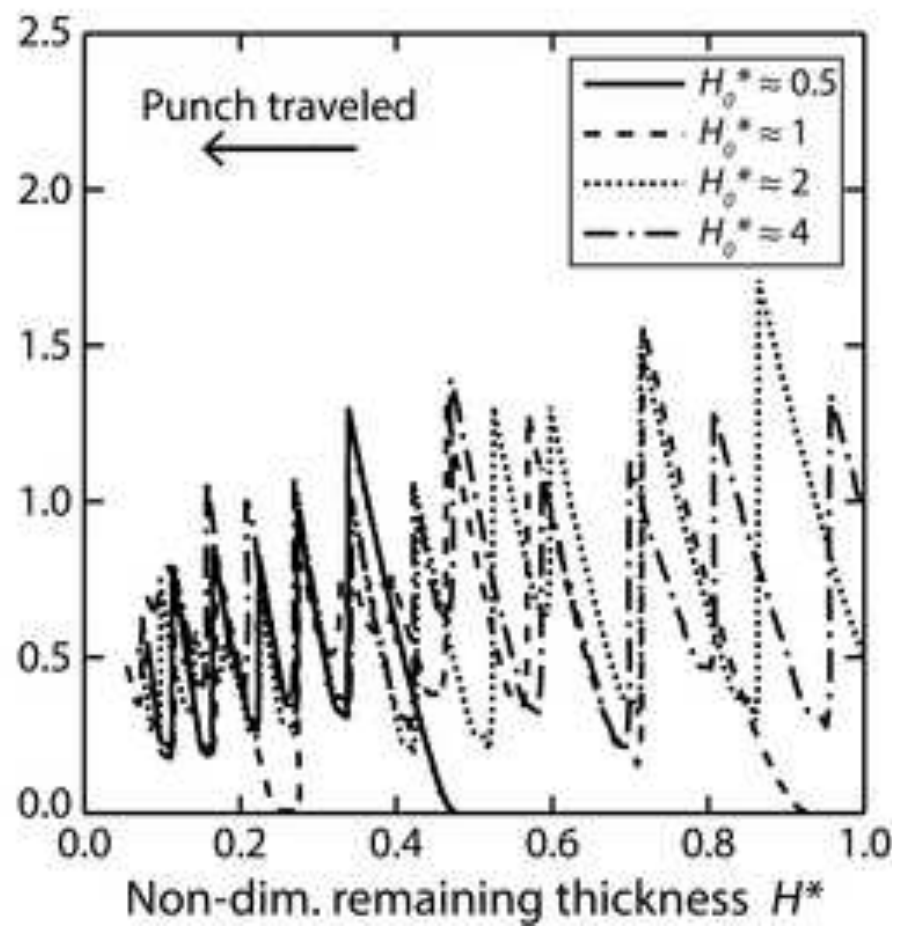


(a) $\mathrm{HB} 26$; vary $\mathrm{H}_{0}^{*}$

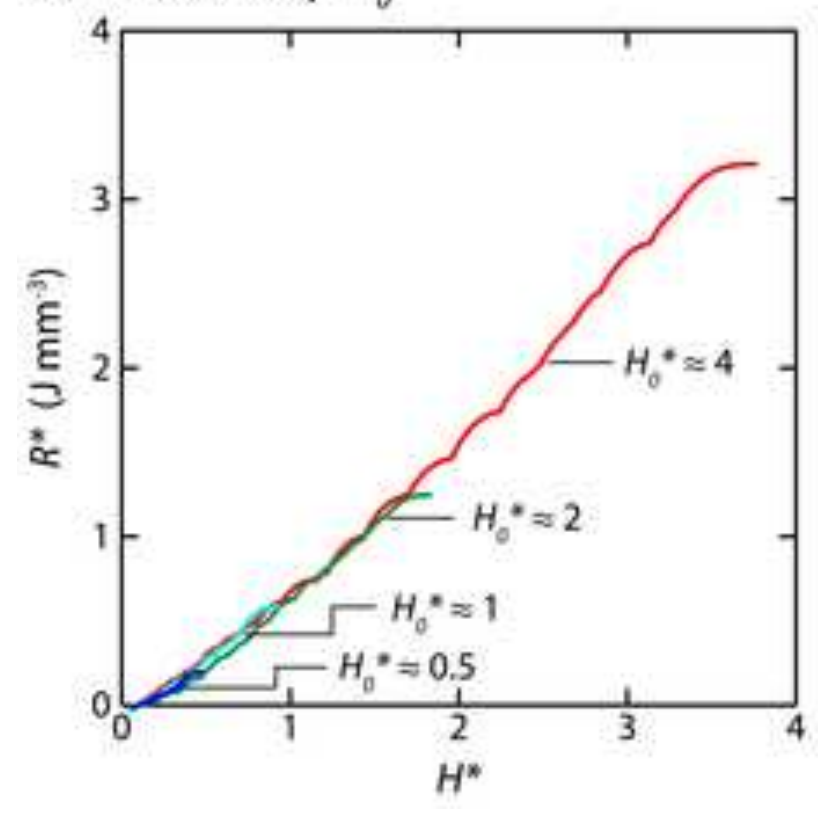

(b) $H_{0}^{*} \approx 3$; all materials

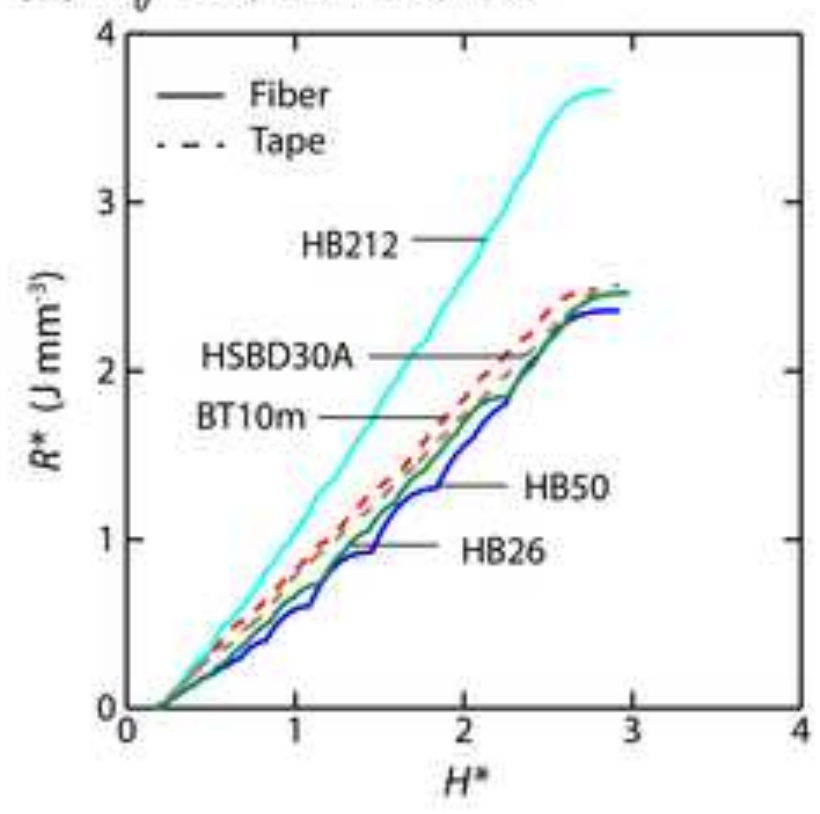

(c) $\sigma_{\sigma}$; all materials

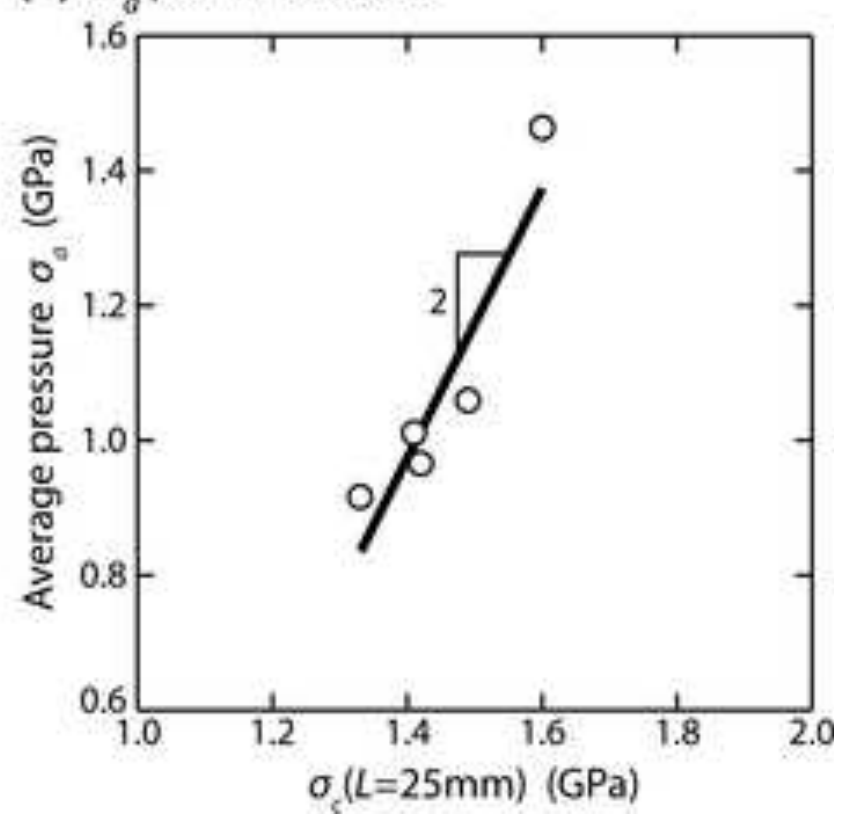


(a) HB26 image, $u_{z}$
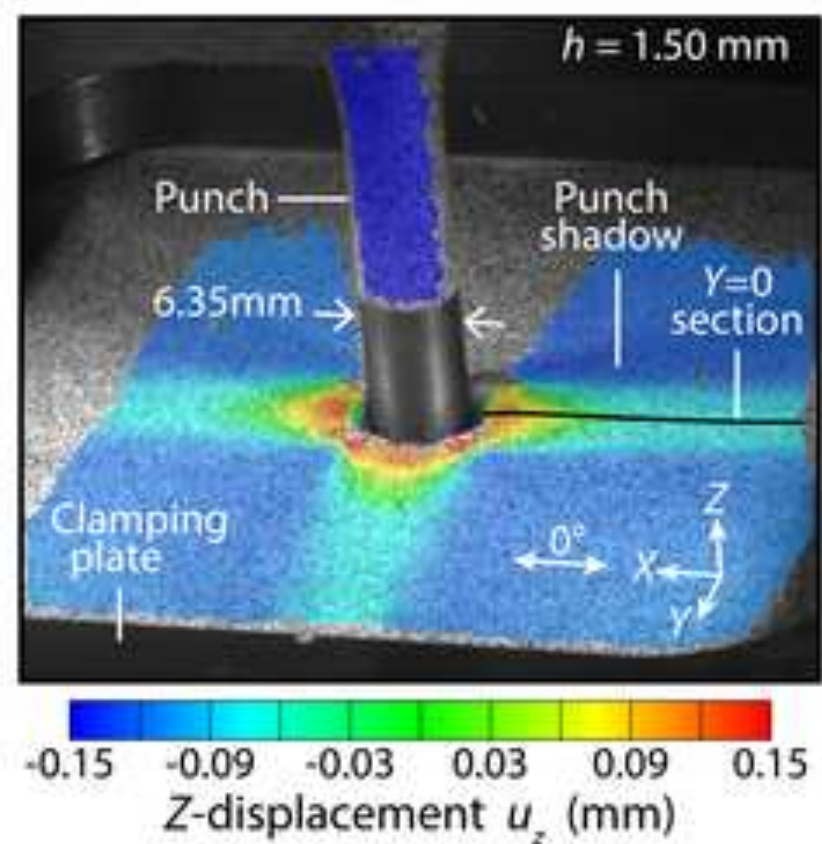

(c) HB50, $u_{x}$

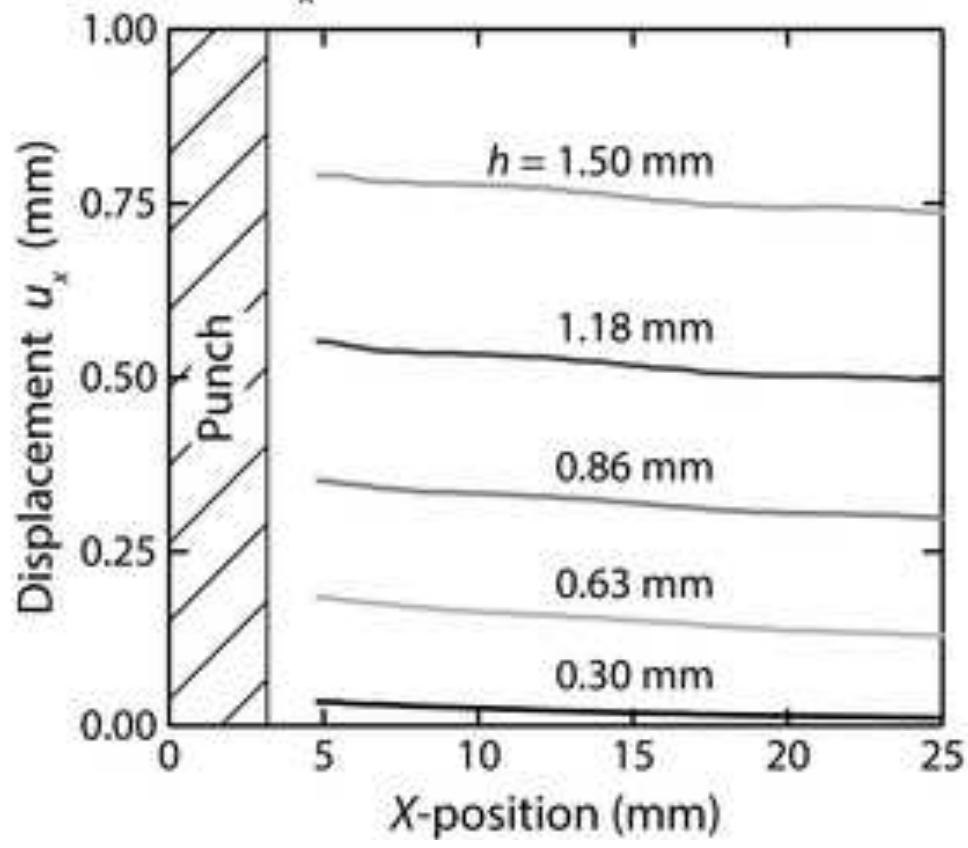

(b) $\mathrm{HB} 50, u_{z}$

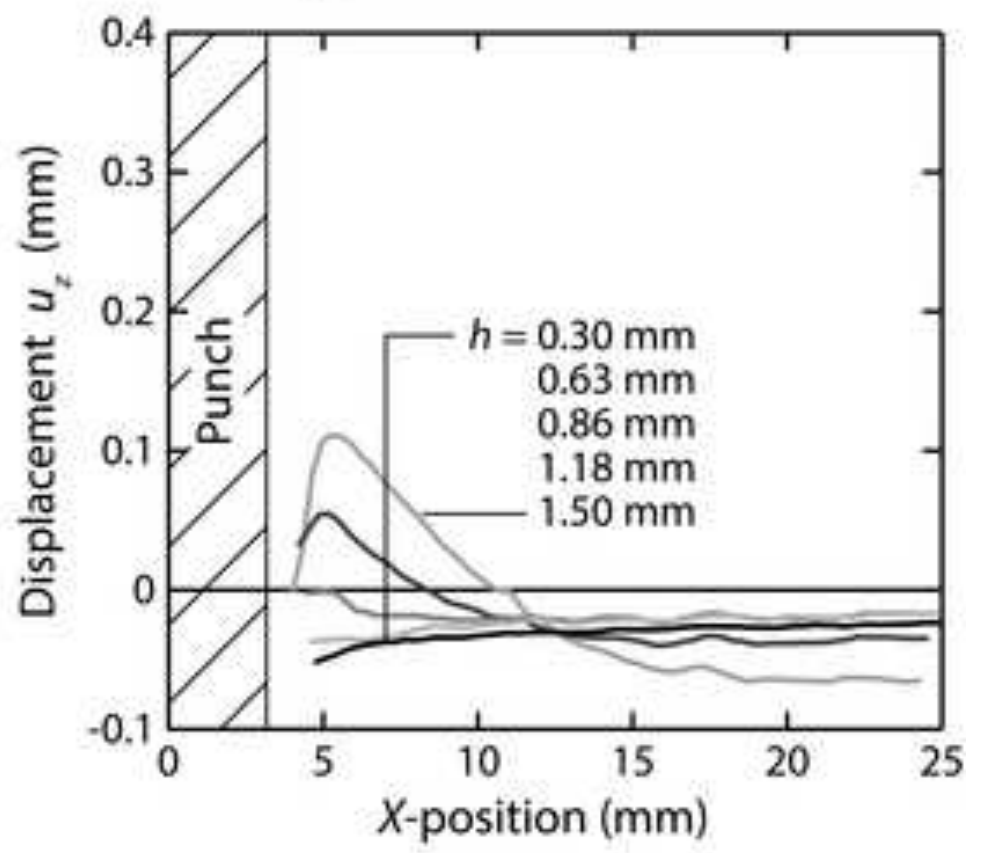

(d) HSBD30A, $u_{z}$

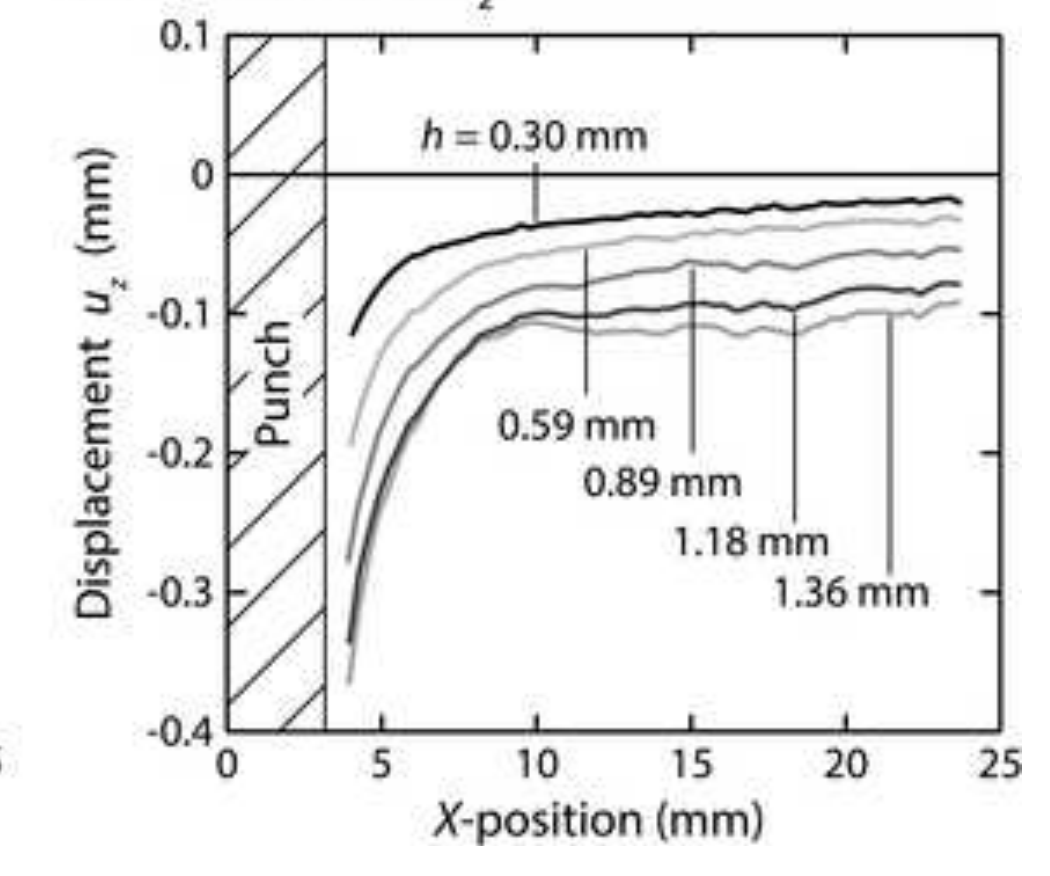

(c) 
(a) HB26
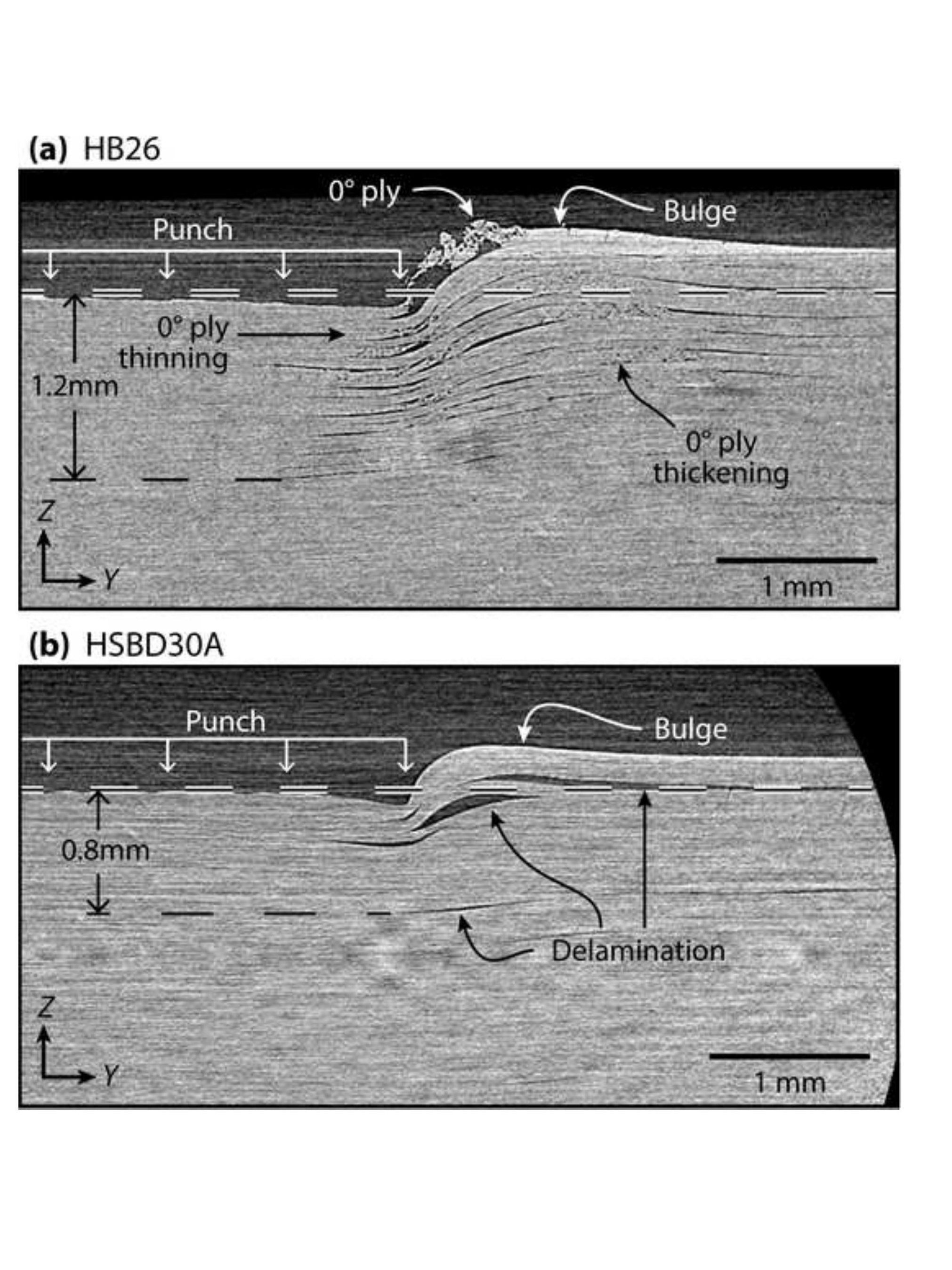

\section{(b) $\mathrm{HSBD} 30 \mathrm{~A}$}

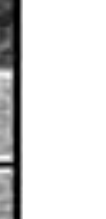$$
\text { - }
$$

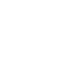


(a) HB50 after initial failure

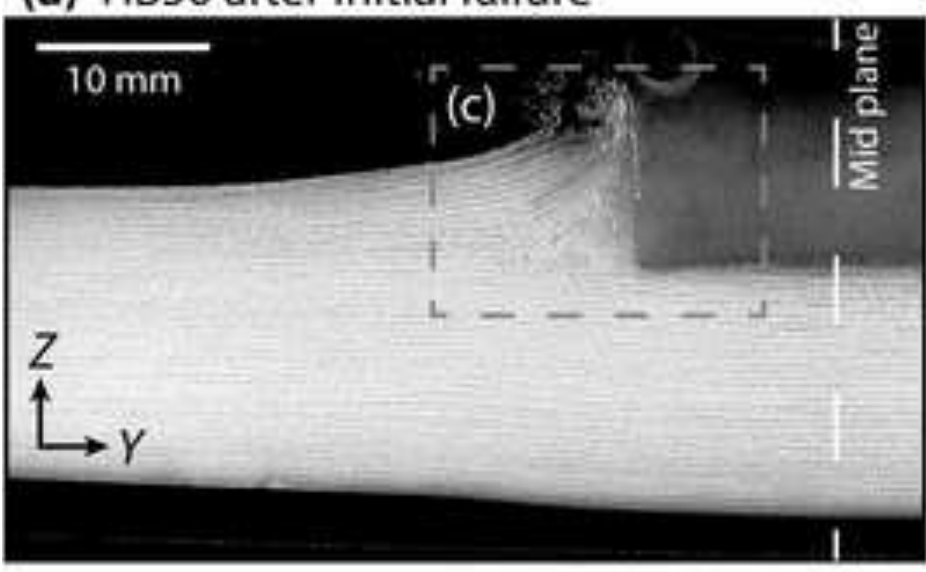

(c) Inset from (a)

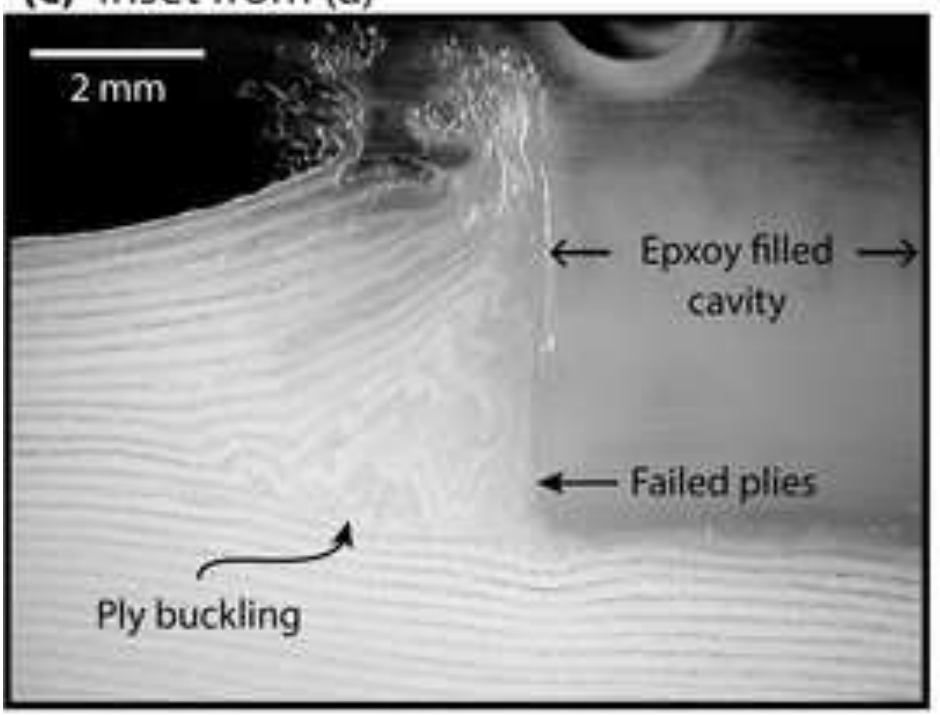

(b) HB50 after second failure

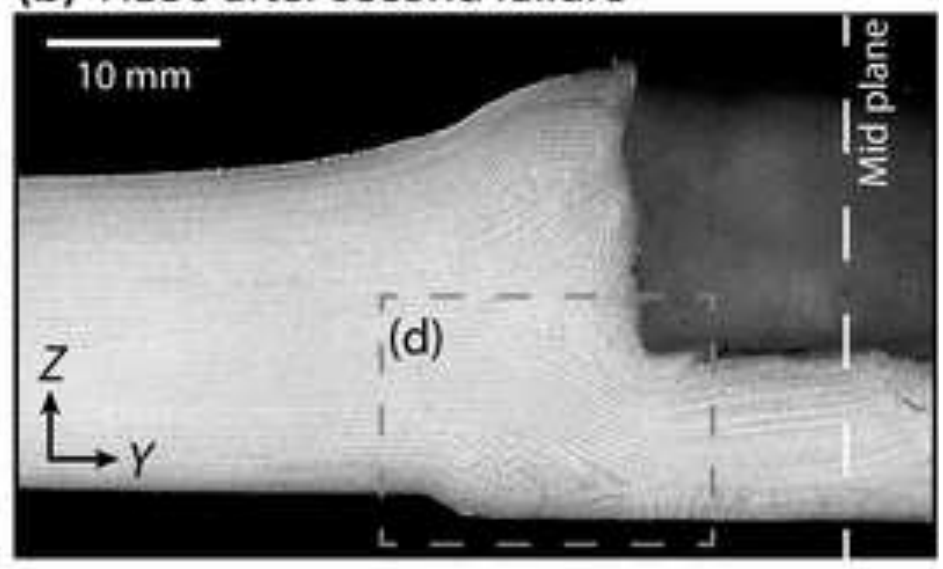

(d) Inset from (b)

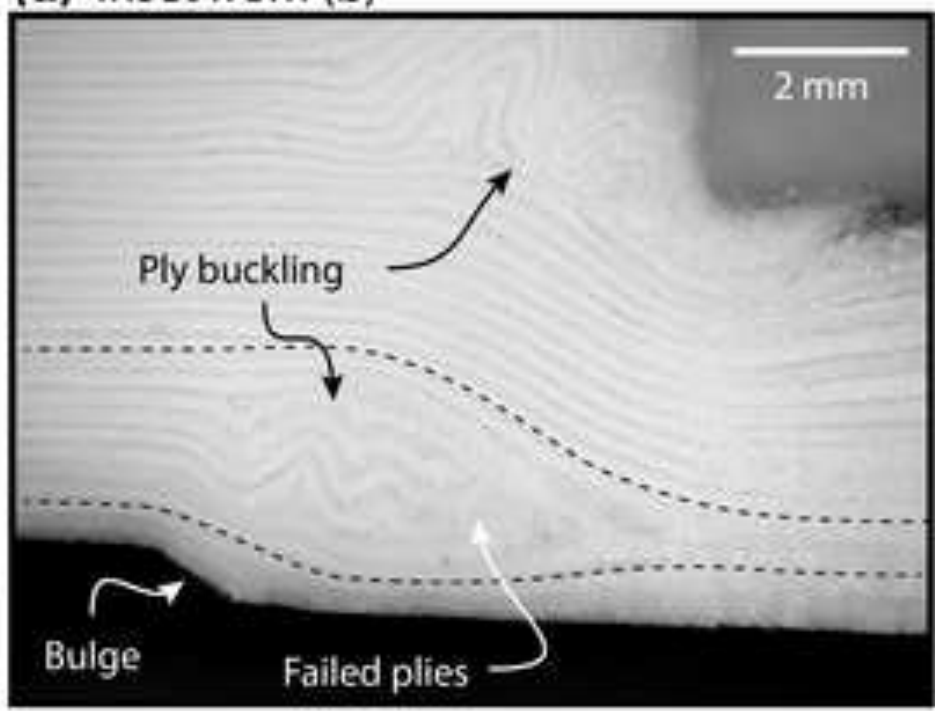

(e) HSBD30A after second failure

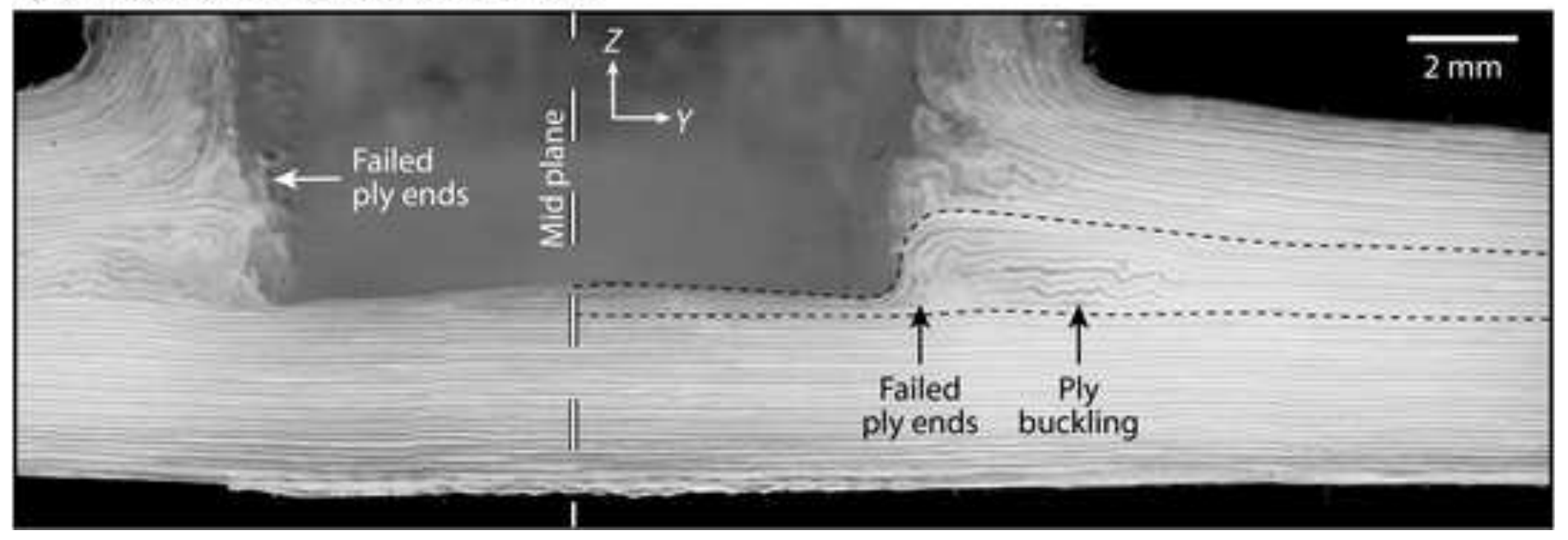




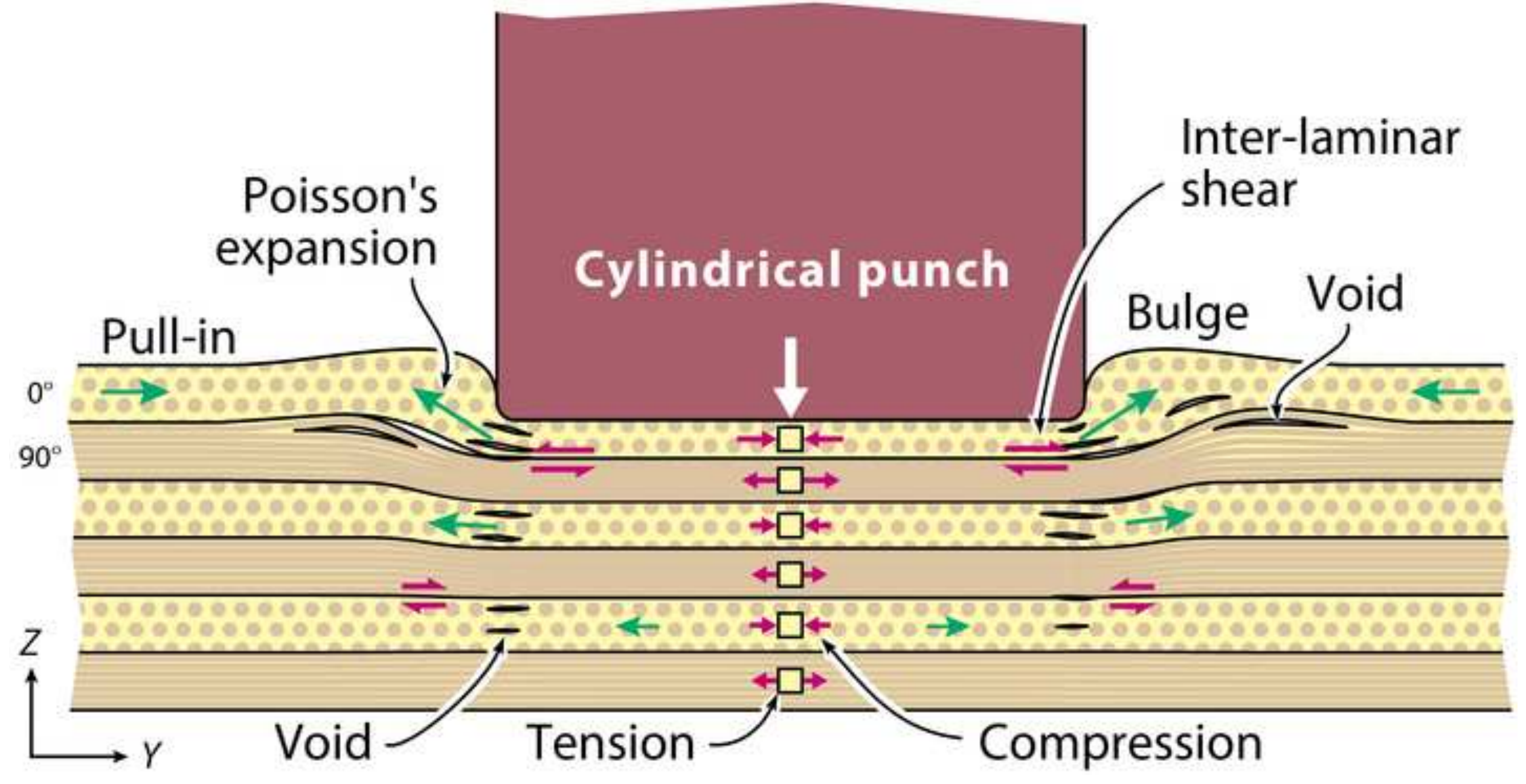

nter-laminar shear Poisson's

Cylindrical punch

0

$0^{\circ}$

Void

Tension

Compression 